ISSN: $1130-2887$ - eISSN: 2340-4396

DOI: https://doi.org/10.14201/alh201879939

\title{
CAMBIO CLIMÁTICO Y CONFLICTIVIDAD SOCIOAMBIENTAL EN AMÉRICA LATINA Y EL CARIBE Climate change and socio-environmental conflicts
}

\author{
Alfredo STEIN \\ Universidad de Mánchester, Reino Unido \\ \Alfredo.Stein@manchester.ac.uk.
}

Fecha de recepción: 22 de febrero de 2018

Fecha de aceptación y versión final: 2 de julio de 2018

RESUMEN: El artículo contribuye a los debates conceptuales y de políticas sobre la relación entre cambio climático, seguridad y conflicto en América Latina y el Caribe, región que experimenta una creciente vulnerabilidad ambiental y social producto de recurrentes fenómenos de clima extremo y altos niveles de inseguridad ciudadana. Se propone una tipología de conflictos generados por las desigualdades entre quienes provocan el fenómeno, quienes más lo sufren y quienes deberían asumir los costos para enfrentar sus consecuencias.

Palabras clave: cambio climático; conflictividad; vulnerabilidad social; desigualdad; América Latina y el Caribe.

ABSTRACT: This article contributes to the conceptual and policy debates on the relationship between climate change, security and conflict in Latin America and the Caribbean, a region that is experiencing a growing environmental and social vulnerability as a result of recurring extreme weather events and high levels of citizen insecurity. The study proposes a typology of conflicts generated by inequalities between those who cause the phenomenon, those who suffer the most, and those who should bear the costs in order to face its consequences.

Key words: climate change; conflict; social vulnerability; inequality; Latin America and the Caribbean. 


\section{INTRODUCCIÓN ${ }^{1}$}

El cambio climático es un problema global con graves dimensiones ambientales, sociales, económicas, distributivas y políticas, y plantea uno de los principales desafíos actuales para la humanidad. Los peores impactos probablemente recaerán en las próximas décadas sobre los países en desarrollo (Francisco I, Encíclica Laudato si’: 22-23).

Actualmente existe suficiente evidencia estadística para probar que el clima está cambiando. El incremento global de las temperaturas promedio en la atmósfera y los océanos durante los últimos cien años, al igual que la variación en la frecuencia e intensidad de los patrones de precipitaciones y de tormentas en diferentes regiones del planeta, así lo demuestran (IPCC 2007, 2012). ¿Qué implicaciones podrían tener estos cambios en los conflictos y las tensiones al interior de naciones diversas, entre países, así como para la seguridad mundial?

El presente artículo intenta contribuir a las discusiones conceptuales y de políticas públicas sobre la relación entre cambio climático, seguridad y conflicto, fijando la mirada sobre América Latina y el Caribe (ALC), región que en las últimas décadas ha experimentado una creciente vulnerabilidad ambiental y social producto de recurrentes fenómenos de clima severo y extremo, al igual que altos niveles de violencia e inseguridad ciudadana. Para ello, el artículo se plantea las siguientes interrogantes: ¿cómo se relaciona el cambio climático con la incidencia de conflictos sociales en ALC? ¿Es posible elaborar una tipología de conflictos ambientales relacionados con las manifestaciones físicas del cambio climático? ¿Cómo podría evolucionar el fenómeno en las próximas décadas?

Para responder a estas preguntas se examinan cuatro desigualdades y relaciones de poder asociadas al cambio climático (Dodman 2015), que pueden influir en cierto tipo de conflictos socioambientales en ALC: las desigualdades sobre quienes han causado el calentamiento global; las desigualdades en quienes sufren los impactos que la variabilidad climática genera; las desigualdades sobre las capacidades en responder a dichos impactos, y las desigualdades en cuanto a quiénes deberían asumir los costos para enfrentar sus efectos. El artículo trata de identificar estas desigualdades y su posible conflictividad asociada a nivel local, al interior de algunos países, entre subregiones de ALC y globalmente. Si bien existe mayor conocimiento sobre la relación cambio climáticoconflictividad a nivel rural, se ha prestado menor atención a estos procesos en zonas urbanas. Por ello, el artículo proporciona ejemplos de áreas rurales y también aborda la problemática climática y las tensiones en zonas urbanas de la región.

Para su elaboración se analizó documentación secundaria de revistas académicas, noticias de prensa, publicaciones de organismos multilaterales, gobiernos nacionales y

1 El autor agradece a Rodrigo Stein, por insumos al presente documento, y a Philipp Horn, Karen Lemus, Carlos Rivas y Caroline Moser, quienes contribuyeron a discusiones sobre el tema. De igual manera, agradece los comentarios y las sugerencias de dos evaluadores anónimos de América Latina Hoy, Revista de Ciencias Sociales, a la primera versión de este artículo. Algunas partes del presente trabajo sirvieron como insumos para un informe mas amplio solicitado por el Programa de las Naciones Unidas para el Desarrollo (PNUD). 
EN AMÉRICA LATINA Y EL CARIBE

organizaciones no gubernamentales (ONG). Además, se realizó una entrevista con un experto en manejo de cuencas y se revisaron los resultados de dos estudios sobre adaptación al cambio climático en Cartagena, Colombia, y Estelí, Nicaragua, en los cuales el autor estuvo involucrado. Al sistematizar la información se trató de discernir entre aquellos conflictos ambientales generados, por ejemplo, como consecuencia de desastres como terremotos, fuga de gases, derrames de contaminantes y otros, así como de aquellos que posiblemente se asocian directa o indirectamente a los impactos de climas extremos y severos (por ejemplo, lluvias y sequías) (véase: Van Jaarsveld Bronkhorst y Bob 2010).

\section{II. ¿CAMBIO CLIMÁTICO, SEGURIDAD Y CONFLICTO?}

Hasta hace poco el cambio climático fue visto como un problema ambiental y de desarrollo. Sin embargo, en la última década y media empezó a identificarse como un serio desafío con amplias repercusiones internacionales en temas de seguridad y conflictos de diversa índole (Schoch 2011). La atención creciente sobre el nexo entre calentamiento global, inestabilidad y paz mundial surge por la preocupación de las disputas potenciales y los conflictos violentos entre naciones y regiones que puedan resultar por la escasez, la falta y/o el limitado acceso a recursos renovables y alimentos, al igual que por los desplazamientos internos masivos de poblaciones y migraciones transnacionales que puedan darse como consecuencia de variaciones significativas en el régimen de precipitaciones y desastres «naturales» asociados, tales como prolongadas sequías, tormentas e inundaciones (IPCC 2001; Reuveny 2007; Scheffran y Battaglini 2011).

En varias ocasiones, el Consejo de Seguridad de la Organización de las Naciones Unidas (ONU) ha dado alta prioridad a los vínculos estratégicos entre cambio climático, inseguridad y conflicto y los ha incluido en su agenda de discusiones (UN 2007; UN 2011). En 2007, el entonces secretario general de la ONU advirtió que:

el cambio climático no sólo tendrá implicaciones ambientales, sociales y económicas serias, sino también puede incrementar el riesgo de conflictos, la escasez de comida y de agua, transformando la competencia pacífica sobre dichos recursos en violencia, y las inundaciones y sequías podrían generar migraciones masivas polarizando sociedades y debilitando las capacidades de los países por resolver sus conflictos de manera pacífica (UN 2007).

Basado en el informe del Panel Intergubernamental sobre Cambio Climático (IPCC 2001), el ministro de Cooperación holandés argumentó en la sesión del Consejo de Seguridad de la ONU que para 2010 habría en el mundo unos 50 millones de «refugiados ambientales», sin tomar en cuenta los efectos futuros del cambio climático, y en 2050 «habría miles de millones de personas sufriendo severamente como consecuencia del declive en la existencia de recursos hídricos» (UN 2007). Sin embargo, varios participantes en las discusiones, entre ellos China y Pakistán -en nombre de los países no alineados-, insistieron en que el impacto del cambio climático debería verse como un problema de desarrollo sostenible que puede tener alguna implicación en el tema de seguridad, pero no como un tema esencialmente de seguridad y conflicto (UN 2007). 
La temática fue retomada en el Informe sobre el Desarrollo Mundial sobre Conflicto, Seguridad y Desarrollo (World Bank 2011), que identificó el cambio climático no como un propulsor, sino como un factor externo que amplifica el riesgo del conflicto y la violencia (con la probable excepción de conflictos sobre el acceso a recursos naturales tales como agua, energía, alimentos y tierra). Si bien el informe del Banco Mundial se centra en las presiones resultantes del cambio climático a nivel regional y subregional, en el contexto de Estados frágiles y países con débil institucionalidad, también reconoce la necesidad de estudiar más de cerca los impactos del cambio de clima sobre la disponibilidad de tierra cultivable y los precios de los alimentos, cada uno de ellos con posibilidades de incrementar el riesgo de conflictos (World Bank 2011).

Estudios como el de Barrett (2014), preparado para la conferencia COP10 en Lima, identifican los desafíos potenciales desde el punto de vista militar estadounidense de las implicaciones del cambio climático como estresor de la situación de seguridad en el mundo, incluyendo diversas subregiones en América Latina. Para México y Centroamérica, el estudio enfatiza la interrelación entre lluvias severas, violencia y debilidad institucional que podría generar migraciones masivas hacia Estados Unidos (EUA). En la cuenca del Caribe igual situación podría darse, especialmente como resultado del impacto de huracanes y el grado de conflictividad existente entre la República Dominicana y Haití; en el Cono Sur (especialmente en Chile y Brasil), posibles episodios de disturbios sociales durante periodos de crisis hídrica podrían suscitarse; y en la zona ecuatorial, el clima podría exacerbar la violencia que existe en las regiones fronterizas entre Venezuela y Colombia (Barrett 2014).

Si bien las condiciones climáticas por sí mismas no pueden causar conflictos, los cambios climáticos pueden alterar las condiciones en las cuales ciertas relaciones sociales se dan y, por lo tanto, tienen el potencial de cambiar las posibilidades que resulten en conflicto (Burke, Hsiang y Miguel 2014). Estos conflictos pueden ser interpersonales -por ejemplo, crímenes, asaltos, violaciones, robos y violencia doméstica o aquellos que se dan en eventos deportivos o en congestiones de tráfico y violencia policial-, pero también pueden ser intergrupales - por ejemplo, la violencia política organizada, las guerras o disturbios sociales, e inclusive invasiones y tomas de tierra, al igual que quiebres institucionales y colapsos poblacionales de carácter histórico (Burke, Hsiang y Miguel 2014)-. En sociedades con renta baja, el clima pareciera afectar directamente las condiciones económicas, mientras que en sociedades con ingresos más altos la correlación entre violencia y clima pareciera obedecer a factores psicológicos. Basados en una revisión de estudios que utilizan modernos enfoques de análisis econométricos, los autores apuntan a que variaciones de un grado en las variables climatológicas pueden incrementar potencialmente en un $14 \%$ la violencia intergrupal, siendo el aumento de la temperatura de mayor impacto que el aumento en el régimen de precipitaciones (Burke, Hsiang y Miguel 2014).

Sin embargo, otros investigadores argumentan que la correlación entre cambio climático, seguridad y conflictos violentos todavía es especulativa y se basa en fuentes no fidedignas, contenciosas y contradictorias, que no proporcionan suficiente evidencia empírica para probar la existencia de estos vínculos (Nordås y Gleditsch 2007). Al 
analizar estudios que correlacionan cuantitativamente el cambio climático y conflictos violentos en África y Asia, tanto en épocas húmedas como áridas, Theisen, Gleditsch y Buhaug (2013) concluyen que el tema debe seguir siendo estudiado pues la evidencia aún es débil e inconclusa.

\section{II.1. Cambio climático, migraciones y conflictos}

Reuveny (2007: 657-668) sostiene que el cambio climático podría causar una severa degradación ambiental que llevaría a mucha gente a abandonar las áreas más afectadas por estos fenómenos, principalmente en países de renta baja, y esto podría a su vez generar tensiones y conflictos entre migrantes y residentes en las áreas receptoras, especialmente cuando estos grupos pertenecen a etnias distintas. Sin embargo, aclara que la mayoría de veces las migraciones por razones ambientales por sí mismas no conducen a conflictos, pero cuando lo hacen pueden generar un alto nivel de conflictividad al interior de un país o entre países, especialmente cuando los lugares receptores de migrantes son menos desarrollados y además son altamente dependientes de sus recursos ambientales para generar los medios de vida de su población (Reuveny 2007).

Analizando datos sobre migraciones ocurridas después de varios huracanes en el Golfo de México y Centroamérica, Smith (2007: 617-623) sostiene que históricamente las migraciones han estado «inextricablemente vinculadas» a fenómenos climatológicos de gran envergadura y, «en la medida en que los estados nacionales tengan que enfrentar estos desastres, o que perciban que hay una migración incontrolada hacia sus territorios, muchos recurrirán a fuerzas militares para enfrentar estos desafíos», aunque no necesariamente lleve a conflictos armados entre naciones. Después del huracán Mitch, hubo una migración masiva de centroamericanos a EUA y, «a su paso por México, muchos de ellos fueron abusados o sufrieron violencia a manos de oficiales de policía y/u oficiales de migración» (Smith 2007: 628). En tal sentido «la militarización de las respuestas estatales hacia las migraciones incluyendo las de EUA, refleja un cambio de paradigma sobre cómo la migración internacional es considerada [...] Ahora, el tema migratorio, que en el pasado era un tema social o laboral, se ha transformado en un tema de seguridad». Smith (2007: 631) afirma que sociedades que de por sí son «proclives al conflicto y que tienen reducidos recursos económicos, políticos y sociales para enfrentar las migraciones vinculadas al cambio climático pueden experimentar mayor inestabilidad social y económica y llegar a puntos de inflexión (tipping points) que conduzcan a mayores inestabilidades e inclusive al fracaso de dichos estados».

Este podría ser el caso de Siria. Kelly et al. (2015) sugieren que el conflicto sirio tiene como una de sus probables raíces la prolongada sequía por tres años consecutivos que provocó la ruina de la producción agrícola y pecuaria del país, forzando una migración masiva de más de 1,5 millones de personas del campo a las periferias de las ciudades, antes de iniciarse la insurrección armada contra el régimen en 2011.

Sin embargo, para algunos científicos, detrás de varios de estos estudios hay concepciones neomaltusianas basadas en la premisa de que el conflicto violento que podría derivarse de los impactos del cambio climático está determinado por 
la escasez de recursos por sí mismos, sin tomar en cuenta las condiciones políticas, socioeconómicas e históricas que pueden conducir a la dependencia y a la conflictividad sobre el control de un recurso que puede ser escaso en determinado momento (Van Leewuwen y Van der Haar 2016). Otros advierten sobre la perversidad implícita al querer transformar el cambio climático y la conflictividad asociada en un tema de seguridad nacional, que podría llevar a la búsqueda de soluciones militares (Rodrigues de Brito 2012).

Barnett y Adger (2007) proponen que un mejor entendimiento entre cambio climático y sus efectos en la seguridad humana requiere más investigación empírica cuantitativa y cualitativa, así como un marco teórico que permita repensar la vulnerabilidad de los medios de vida de la gente a cambios climáticos y los estreses que puedan conducir a conflictos violentos. Para ellos, los hallazgos contradictorios en relación a los cambios ambientales derivados del calentamiento global y los conflictos podrían resultar del «tipo de conflictos estudiados, los diferentes tipos de cambios ambientales examinados y los diferentes períodos de tiempo y localidades estudiados» (Bernauer, Bhömelt y Koubi 2012: 4).

\section{LA BÚSQUEDA DE UN MARCO CONCEPTUAL}

El conflicto social en sus diversas manifestaciones (bien sean controversias, antagonismos, demandas, luchas, reivindicaciones, protestas, resistencias, enfrentamientos $\mathrm{y}$, en casos extremos, violencia) se alimenta de relaciones desiguales de poder, tanto reales como históricas (Calderón et al. 2012). Si bien las desigualdades por sí mismas no desembocan necesariamente en conflictos y mucho menos en violencia, el Programa de Naciones Unidas para el Desarrollo (PNUD) sostiene que los países latinoamericanos que más conflictos tienen son aquellos donde hay mayores desigualdades sociales (Calderón et al. 2012). En la mayoría de casos estos conflictos se manejan y resuelven de manera pacífica a través de diversos mecanismos sociales, culturales y políticos, pero en ocasiones se puede llegar a la violencia si tales mecanismos no son capaces de contener los conflictos (Moser y Horn 2012).

Hoy se sabe que las consecuencias del cambio climático afectan más a ciertas naciones y grupos sociales que a otros. Quién gana o quién paga las consecuencias del cambio climático requiere, por lo tanto, indagar sobre la multiplicidad de relaciones de poder y las diferentes escalas en las cuales estas relaciones desiguales se «producen, reproducen y mantienen» (Swyngedouw y Heynen 2004). Por ello, plataformas socioecológicas y organizaciones ambientalistas insisten en que el cambio climático «no es una catástrofe ambiental que puede ser afrontada con instrumentos del mercado, sino como una crisis social profunda del sistema económico capitalista» (Brunnengräber 2014). Dodman (2015) propone indagar la forma en que el cambio climático influencia, o es influenciado, por cuatro tipos de desigualdades:

a) las desigualdades asociadas con las causas del cambio climático, las cuales pudieran generar conflictos entre naciones sobre la responsabilidad que cada 
país tiene en cuanto al origen del problema, es decir, su contribución actual y también a la acumulación histórica de emisión de gases de efecto invernadero (GEI), que generan el calentamiento global;

b) las desigualdades asociadas con los impactos del cambio climático, que pudieran propiciar conflictos entre Estados sobre la relación que existe entre la responsabilidad en la generación del problema y aquellas naciones que en estos momentos sufren más los impactos negativos (económicos y sociales) de la variabilidad en los patrones de clima asociados al cambio climático;

c) las desigualdades en cuanto a la capacidad de responder a los impactos del cambio climático, es decir, su capacidad de adaptación y de construcción de resiliencia (tanto entre países como al interior de países; entre áreas rurales y urbanas; y al interior de distintas áreas de una ciudad al igual que entre distintos grupos sociales y de poder);

d) las desigualdades en cuanto a quiénes deberían asumir los costos asociados para prevenir las emisiones de gases de efecto invernadero e incrementar la capacidad de adaptación al impacto de fenómenos de clima severo y extremo, asociados al cambio climático.

A continuación se indaga la posible relación de cada una de estas desigualdades con la conflictividad socioambiental en ALC. Para cada desigualdad se identifican casos que ilustran el posible vínculo. No se trata de generalizar o demostrar dicha relación, pues ello requiere de investigaciones de mayor profundidad y alcance. Lo que se pretende es mostrar situaciones que están ocurriendo y que podrían reflejar tendencias cada vez más evidentes y recurrentes en la región, y de la cual investigadores, hacedores de política y las comunidades que sufren sus consecuencias están tomando cada vez más conciencia.

\section{III.1. La desigual contribución a las causas y consecuencias del cambio climático}

El tema de la «equidad es central en las discusiones sobre política climática a nivel nacional e internacional, dado que los que son menos responsables en la generación del problema, es decir, aquellos que ya de por sí son vulnerables por las condiciones de pobreza y marginalidad en las que viven, son los que enfrentan los mayores riesgos de ser afectados por el cambio climático; e inversamente, aquellos que más han contribuido al cambio climático son los que mayores capacidades tienen para enfrentar a estos impactos» (WRI 2015).

En repetidas reuniones mundiales en las últimas décadas han salido a relucir estas desigualdades y la necesidad de mayor equidad entre naciones. Por ejemplo, los representantes de China, India, Brasil y Sudáfrica que lideraron las negociaciones de sus países en la COP21 en París, y que por su peso e influencia ascendente en la palestra mundial parecieran también hablar por el resto de países en vías de desarrollo, han insistido en que existen «responsabilidades comunes pero diferenciadas» para abordar las causas del problema y que, por lo tanto, «los países desarrollados son los 
que deben asumir los mayores esfuerzos en abordar las causas y consecuencias del cambio climático» (El País 8/12/15).

Una mirada a la contribución histórica que ALC ha tenido en la emisión de gases de efecto invernadero (GEI) (incluyendo los cambios producidos en el uso del suelo, las actividades agropecuarias y los bosques) muestra que, en su conjunto, la región contribuyó únicamente con el 10\% de los GEI a nivel mundial en 2012, aunque México y Brasil juntos contribuyeron con un 5,4\% y los otros 31 países de ALC, con el 4,6\% de los GEI (véase: Tabla I).

Al ver de cerca la relación entre el índice de riesgo climático de cada país y su contribución a la emisión de GEI, la desigualdad entre los que generan el problema y los que más sufren sus impactos es evidente. 5 de los 10 países a nivel mundial con más riesgo al cambio climático están en Centroamérica y el Caribe (véase: Tabla I): Honduras, que ocupaba el rango 1 a nivel mundial, contribuyó únicamente con el 0,1\% de la producción mundial de los GEI en 2012; mientras que Haití, con el rango 3, produjo el 0,017\%; Nicaragua, con el rango 4, emitió el 0,09\%; República Dominicana, con el puesto 8, produjo el 0,066\%, y Guatemala, en el noveno, produjo el 0,083\% (véase: Tabla I).

Los países ecuatoriales y andinos (Bolivia, Perú, Ecuador, Colombia y Venezuela) ocupan rangos menos críticos en su índice de riesgo, aunque su contribución de GEI es un tanto superior, pero no demasiado, respecto a la región centroamericana y caribeña, mientras países del Cono Sur (Argentina, Brasil, Paraguay y Uruguay) se ubicaban en países con rangos superiores a otras regiones de ALC (véase: Tabla I).

\section{TABLA I}

ÍNDICE DE RIESGO CLIMÁTICO (1994-2013), CAPACIDAD ADAPTATIVA, EMISIÓN DE GASES DE EFECTO INVERNADERO (GEI) Y CONTRIBUCIÓN DE CADA PAÍS DE ALC

\section{A LA EMISIÓN DE GEI EN 2012}

\begin{tabular}{|c|c|c|c|c|}
\hline PAís & $\begin{array}{l}\text { RANGO PAÍs } \\
\text { SEGÚN ÍNDICE } \\
\text { DE RIESGO } \\
\text { CLIMÁTICO } \\
(1994-2013)^{1}\end{array}$ & $\begin{array}{l}\text { ÍNDICE DE } \\
\text { CAPACIDAD } \\
\text { ADAPTATIVA } \\
\text { AL CAMBIO } \\
\text { CLIMÁTICO* }\end{array}$ & $\begin{array}{l}\text { TOTAL EMISIONES } \\
\text { GEI POR PAÍS } \\
\text { (INCLUYENDO } \\
\text { CAMBIO USO } \\
\text { DE SUELO Y } \\
\text { BOSQUES) EN } 2012 \\
\left(\mathrm{MTCO}_{2} \mathrm{E}\right) \\
\end{array}$ & $\begin{array}{l}\text { CONTRIBUCIÓN } \\
\text { DE CADA PAÍS A LA } \\
\text { EMISIÓN TOTAL } \\
\text { DE GEI A NIVEL } \\
\text { MUNDIAL EN } 2012 \\
\text { (EN PORCENTAJE) }\end{array}$ \\
\hline $\begin{array}{l}\text { Antigua y } \\
\text { Barbuda }\end{array}$ & 32 & Medio & 1.1365 & 0,002 \\
\hline Argentina & 80 & Medio & 405.0348 & 0,851 \\
\hline Bahamas & 31 & Bajo & 4.1728 & 0,009 \\
\hline Barbados & 135 & Bajo & 3.3496 & 0,007 \\
\hline Belice & 21 & Alto & 14.5934 & 0,031 \\
\hline Bolivia & 33 & Extremo & 136.4737 & 0,287 \\
\hline Brasil & 78 & Bajo & 1.823 .1480 & 3,830 \\
\hline
\end{tabular}


ALFREDO STEIN

CAMBIO CLIMÁTICO Y CONFLICTIVIDAD SOCIOAMBIENTAL

EN AMÉRICA LATINA Y EL CARIBE

\begin{tabular}{|c|c|c|c|c|}
\hline PAÍS & $\begin{array}{l}\text { RANGO PAÍs } \\
\text { SEGÚN ÍNDICE } \\
\text { DE RIESGO } \\
\text { CLIMÁTICO } \\
(1994-2013)^{1}\end{array}$ & $\begin{array}{l}\text { ÍNDICE DE } \\
\text { CAPACIDAD } \\
\text { ADAPTATIVA } \\
\text { AL CAMBIO } \\
\text { CLIMÁTICO* }\end{array}$ & $\begin{array}{l}\text { TOTAL EMISIONES } \\
\text { GEI POR PAÍS } \\
\text { (INCLUYENDO } \\
\text { CAMBIO USO } \\
\text { DE SUELO Y } \\
\text { BOSQUES) EN } 2012 \\
\text { (MTCO }_{2} \text { E) }\end{array}$ & $\begin{array}{c}\text { CONTRIBUCIÓN } \\
\text { DE CADA PAÍS A LA } \\
\text { EMISIÓN TOTAL } \\
\text { DE GEI A NIVEL } \\
\text { MUNDIAL EN } 2012 \\
\text { (EN PORCENTAJE) }\end{array}$ \\
\hline Chile & 100 & Bajo & 93.73861 & 0,197 \\
\hline Colombia & 43 & Medio & 199.6809 & 0,420 \\
\hline Costa Rica & 60 & Bajo & 4.9727 & 0,010 \\
\hline Cuba & 53 & Bajo & 34.7922 & 0,073 \\
\hline Dominica & 35 & Medio & 0.31866 & 0,001 \\
\hline Ecuador & 51 & Alto & 138.1583 & 0,290 \\
\hline El Salvador & 12 & Extremo & 13.0686 & 0,027 \\
\hline Granada & 13 & Medio & 1.9443 & 0,004 \\
\hline Guatemala & 9 & Extremo & 39.2748 & 0,083 \\
\hline Guayana & 88 & Extremo & 7.6371 & 0,016 \\
\hline Haití & 3 & Extremo & 7.9051 & 0,017 \\
\hline Honduras & 1 & Extremo & 47.7017 & 0,100 \\
\hline Jamaica & 48 & Medio & 9.5853 & 0,020 \\
\hline México & 38 & Bajo & 748.9118 & 1,573 \\
\hline Nicaragua & 4 & Extremo & 42.7008 & 0,090 \\
\hline Panamá & 90 & Medio & 22.0508 & 0,046 \\
\hline Paraguay & 45 & Extremo & 110.9796 & 0,233 \\
\hline Perú & 50 & Medio & 159.4985 & 0,335 \\
\hline $\begin{array}{l}\text { República } \\
\text { Dominicana }\end{array}$ & 8 & Extremo & 31.1844 & 0,066 \\
\hline St Kitts y Nevis & 39 & Medio & 0.3393 & 0,001 \\
\hline St Lucia & 35 & Medio & 1.4386 & 0,002 \\
\hline $\begin{array}{l}\text { St Vincent y } \\
\text { Las Granadinas }\end{array}$ & 46 & Medio & 0.3151 & 0,001 \\
\hline Surinam & 151 & Alto & 8.6304 & 0,018 \\
\hline $\begin{array}{l}\text { Trinidad y } \\
\text { Tobago }\end{array}$ & 142 & Medio & 40.4024 & 0,085 \\
\hline Uruguay & 68 & Bajo & 14.7594 & 0,031 \\
\hline Venezuela & 54 & Alto & 396.7376 & 0,834 \\
\hline
\end{tabular}

Notas: ${ }^{1} \mathrm{Si}$ un país se encuentra en el rango entre 1 y 10, enfrenta mayores riesgos de sufrir impactos del cambio climático. *Cuanto más alto el índice, menor capacidad de adaptación y por ello se le considera extremo. Cuanto más bajo, mayor capacidad de adaptación del país y, por lo tanto, su capacidad de adaptación será mayor.

Fuente: Elaboración propia con base es S. KREFT et al. (2014); CAF (2014: 63) y WRI (2015). 
De hecho, los países de Centroamérica y el Caribe poseen algunos de los niveles más altos de vulnerabilidad a desastres naturales asociados a fenómenos climáticos y muchos de ellos tienen las menores capacidades institucionales y recursos para el manejo de desastres en la región de ALC (BID 2010). Por ejemplo, entre 1930 y 2008, Centroamérica sufrió 248 eventos extremos asociados a fenómenos hidrometeorológicos y climáticos (CEPAL 2011: 65). Entre 1992 y 2009, las pérdidas económicas en Centroamérica asociadas a eventos de clima severo y extremo ascendían aproximadamente a US\$10.6 millardos (Stein 2014). Debido a estas circunstancias, la posición de los países centroamericanos y de la República Dominicana presentada ante la COP21 de París en 2015 recalcó la existencia de estas desigualdades a nivel global y llamó a los países desarrollados a asumir los costos de lo que ellos han generado y de los cuales la subregión sufre con mayor intensidad ${ }^{2}$.

La vulnerabilidad de cada país al cambio climático está determinada por la exposición a fenómenos extremos, la sensibilidad de los seres humanos y sus recursos a esa exposición y la capacidad que cada país tiene para adaptarse a los impactos potenciales de esos fenómenos. La Tabla I muestra las diferencias en las capacidades adaptativas de la región: países como Haití, Nicaragua, Honduras, Guatemala, Guayana, Bolivia, Paraguay, El Salvador y República Dominicana son los que tienen un puntaje más bajo en cuanto a su capacidad adaptativa y, por lo tanto, su condición es extrema, mientras que México, Costa Rica, Chile, Cuba, entre otros, los que mayor capacidad tienen.

\section{III.2. Desiguales impactos, estrés hídrico y conflictividad}

Siguiendo los hallazgos del IPCC $(2001,2007)$, Agnew y Woodhouse (2011: 109110) argumentan que el mayor estrés sobre el agua como consecuencia del cambio climático ocurrirá en África, exacerbando su impacto en la agricultura y posiblemente reduciendo la cosecha de productos dependientes de lluvias en un 50\% para 2020. Si bien en el sudeste de Asia la producción de granos podría incrementarse, en algunas regiones del sudeste asiático y de Asia central la producción decrecerá debido a la desaparición paulatina de los glaciares, principales fuentes de agua para dicha producción. A nivel mundial, las fuentes de agua fresca en zonas costeras también se verían afectadas por el incremento de los niveles del mar, causando intrusiones salinas en las capas freáticas. En ALC se espera un incremento en los procesos de desertificación y el reemplazo de bosques tropicales por sabanas semiáridas o áridas, que tendrá impactos severos sobre la generación de los recursos hídricos (Agnew y Woodhouse 2011). La pregunta obligada es si estos procesos generarán algún nivel de conflictividad y violencia.

Para Agnew y Woodhouse (2011:252), la forma en que se distribuye el agua determina el acceso a dicho recurso (especialmente, su coste). Sin embargo, las inequidades

2 Véase: http://www.marn.gob.sv/centroamerica-y-republica-dominicana-acuerdan-posicionregional-para-cumbre-de-cambio-climatico-de-paris/. 
en el acceso al agua reflejan «diferencias de poder que subyacen en las relaciones sociales» y, en cada caso, «no es la escasez del agua la que crea la inequidad en el acceso, sino los procesos sociales que distribuyen inequitativamente el poder económico y político y que median en el tema de la escasez». Son estas inequidades las que pueden generar conflictos a la luz de las implicaciones del cambio climático sobre el manejo y la gestión del recurso hídrico para que sea disponible y accesible cuando se necesite por distintas poblaciones y sectores sociales.

Este planteamiento concuerda con el análisis de Fernández-Jauregui (1999), quien sostiene que el incremento constante de su demanda y siendo un recurso renovable pero finito cuya calidad se deteriora constantemente, «el agua efectivamente fue, es y seguirá siendo una fuente de poder, así como un elemento susceptible de generar conflictos entre países, departamentos, provincias, ciudades, e incluso barrios de la misma población» en América Latina. Al respecto, Hertel et al. (2010) coinciden en que el cambio climático tendrá implicaciones en el ciclo del agua, provocando con ello un alza en los precios de los productos agrícolas que exacerbará los niveles de pobreza en varios países. Sin embargo, no está del todo claro si ello conllevará un mayor grado de conflictividad.

Resumiendo los debates sobre «seguridad sostenible» hechos con expertos latinoamericanistas, Zala (2010: 2) sostiene que la ausencia de una cultura de equidad y de protección social hará que el cambio climático exacerbe conflictos existentes en torno al acceso a recursos en ALC. Existen ya conflictos «de baja intensidad, especialmente vinculados al acceso al agua en varias zonas rurales en América Latina, que si bien no llegan a los titulares de prensa, podrían degenerar en violencia». Es más, los fenómenos ambientales relacionados con el cambio climático ya están afectando de manera «omnipresente los medios de vida de las personas en la región» (Zala 2010).

Sin lugar a dudas, el agua constituye uno de los primeros factores a través del cual el cambio climático afectará los ecosistemas terrestres y marítimos y los medios de vida de la gente, y por ello podría agudizar ciertos conflictos latentes o que ya han aflorado en la región. Los siguientes ejemplos de América Central y la región andina y del Cono Sur -así como los expuestos en el Anexo I- se utilizan para ilustrar estos posibles vínculos.

\section{III.2.1. América Central}

El débil ordenamiento territorial en América Central no solo generará un mayor estrés hídrico, sino también puede potenciar la agudización de conflictos sociales por las constantes pérdidas económicas que le acompañan (Saini 2007). Al respecto, la Comisión Económica para América Latina y el Caribe (CEPAL) (2011) estima que, para el año 2025, podría incrementarse en un $70 \%$ el número de personas con dificultades de acceso a agua potable en América Central. CEPAL (2011) plantea un difícil escenario para los próximos cincuenta años: la demanda de agua podría crecer casi un $300 \%$, siendo El Salvador, Honduras y Nicaragua los países que llegarían a sufrir estrés hídrico por una combinación de cambios en la demanda y el cambio climático. El impacto sobre los recursos hídricos de la región se vería reflejado en cambios en la disminución 
de los caudales en las estaciones de sequía, acompañados de aumentos en la temperatura; mientras que en la estación de lluvia se incrementaría la posibilidad de eventos extremos generando mayores posibilidades de deslizamientos, mayor humedad y pérdidas de cultivos (Estado de la Región 2011). Esta situación se verá acentuada por el acelerado ritmo de urbanización que no contará con la infraestructura adecuada que le permita a la población más pobre acceder efectivamente a servicios básicos (CEPAL 2011; Gardner-Outlaw y Engleman 1997). Así, los cambios en la demanda de agua en América Central obedecerán a una combinación de crecimiento poblacional, agravada por el hecho de que el $75 \%$ de la población asentada en grandes y medianas ciudades se abastece de agua subterránea y esta provisión se verá afectada por el impacto del cambio climático reflejado en variaciones de las precipitaciones y el aumento de salinidad, agroquímicos y aguas residuales en los acuíferos. Esto hace peligrar la disponibilidad del recurso natural en la región (CEPAL 2010).

\section{III.2.2. Región Andina}

De acuerdo a la Secretaría General de la Comunidad Andina (2008), durante las últimas tres décadas la región de los Andes centrales registró un calentamiento un $70 \%$ mayor al promedio global para el mismo periodo. Los cambios de temperatura y humedad han reducido drásticamente los glaciares. La continuidad de este ritmo de incrementos de temperatura significaría la desaparición completa de los glaciares en los próximos quince años (IPCC 2007). El complejo problema de desglaciación de los Andes, en donde se produce el 10\% del agua del planeta, ya representa serios desequilibrios en el Cono Sur, vulnerando a las poblaciones que habitan esta zona con grandes implicaciones para ciudades como Quito, Lima y La Paz (Secretaría General de la Comunidad Andina 2008; Alfaro 2008).

\section{III.2.3. Bolivia}

En un estudio sobre percepciones sobre cambios en el clima y sus efectos, Chaplin (2009) muestra el incremento de vulnerabilidades de familias pobres en el altiplano boliviano producto de la recurrencia y aceleración de sequías e inundaciones severas en los últimos años. Estos fenómenos, aunados al crecimiento de la población en zonas donde ha existido un uso colectivo de tierras comunales, están provocando la desaparición de prácticas de rotación de cultivos, lo cual puede generar impactos insospechados para estas poblaciones.

\section{III.2.4. Argentina}

Dada la extensión geográfica y diversidad de climas existentes, un análisis ecorregional con escenarios heterogéneos podría determinar los posibles impactos del cambio 
EN AMÉRICA LATINA Y EL CARIBE

climático en la conflictividad en los usos del suelo y los recursos hídricos en Argentina (Lumerman, Psathakis y Ortiz 2011). La menor disponibilidad del recurso hídrico para la agricultura afectará la productividad de cultivos que requieran grandes cantidades, o en zonas donde este recurso de por sí es escaso, lo cual obligará a recurrir a explotaciones de agua subterránea, al uso de nuevas tecnologías y/o al cambio de patrones de producción y consumo de la población en favor de una utilización más eficiente del recurso (Lumerman, Psathakis y Ortiz 2011). Según estos autores, por sus características naturales y climáticas, la región del Cuyo ya sufre escasez de agua y a la dificultad de distribuir equitativamente este recurso, se suma su disminución producto del cambio climático. Mendoza es una de las provincias que van a sufrir los impactos de este fenómeno especialmente en la vitivinicultura -una de sus principales actividades económicas-, que depende no solo de disponibilidad de agua, sino también de la amplitud térmica característica de este lugar, dos aspectos afectados por el calentamiento global.

\section{III.2.5. Perú y Chile}

En las costas de Perú y Chile la corriente de Humboldt ha generado un ecosistema del cual se extrae el 10\% de la captura de peces del mundo, beneficiando a cientos de miles de familias que viven de esta actividad (IDR 2015). El impacto del cambio climático ha acentuado fenómenos de desoxigenación y acidificación en dicha corriente, provocando que algunas especies marinas abandonen la zona, mientras que otras especies -como la anchoveta peruana- proliferen y se ubiquen en un hábitat más reducido (IDR 2015). La concentración de dicha especie en las áreas costeras cercanas entre Chile y Perú ha llevado a su sobrepesca y a acusaciones mutuas entre gremios pesqueros de ambas naciones, agravando el grado de conflictividad existente entre los dos países debido a su histórico diferendo limítrofe (SNP 2013).

\section{III.3. Conflictos climáticos asociados a las cuencas de los ríos}

En el marco del cambio climático, la existencia de suficiente cobertura vegetal a lo largo de las cuencas de los ríos constituye uno de los principales elementos que servirá para prevenir las inundaciones que se generen en caso de lluvias frecuentes e intensas de corta duración, y también para garantizar la distribución del agua en caso de prolongadas sequías. Si la cobertura vegetal es baja, no habrá capacidad de la cuenca para infiltrar el agua de lluvia y el impacto de las inundaciones se sentirá en poblaciones aledañas a los márgenes del cauce del río, al igual que en los campos de cultivo circundantes.

Las inundaciones frecuentes generarán un serio proceso de erosión al colmatar el lecho de los ríos con depósitos de sedimentos que elevan el nivel del lecho.

3 Esta sección se basa en una entrevista con el Dr. Carlos Rivas, experto en manejo de cuencas, realizada en Tegucigalpa, Honduras, a finales de marzo de 2016. 
Consecuentemente, las lluvias subsiguientes, inclusive aquellas de corta duración, generarán inundaciones. Por ello, cuanto mayor el tiempo de concentración de una cuenca hidrográfica, es decir, el tiempo necesario para que el caudal saliente se estabilice cuando ocurre una precipitación con intensidad constante, los beneficios serán mayores. Pero, si el tiempo de concentración es menor, se agudizarán los problemas de contaminación del recurso hídrico.

El ideal sería que las cuencas de los ríos mantengan su integridad ecológica para que pueda asegurarse cobertura vegetal suficiente para mantener y aumentar la producción del recurso hídrico. Sin embargo, la cobertura vegetal en muchos países de ALC se ve amenazada y afectada por la deforestación vinculada a la comercialización de la madera, los incendios forestales, los cambios en el uso de suelos, los procesos de urbanización, así como por el incremento en el uso de la leña para cocinar.

En ALC hay muchos asentamientos humanos en las áreas de infiltración de las cuencas y en las márgenes de los ríos. Por ello, es previsible que en la época seca los conflictos sobre el agua se agudicen por la reducción de los caudales, y en época de lluvias, por el incremento de los grandes caudales debido a la falta de la cobertura vegetal. En este contexto, las crecientes invasiones de terrenos en montañas y terrenos claves donde se ubica la cobertura vegetal necesaria para la regulación del recurso hídrico constituye otro factor de tensiones que podría agudizar los conflictos sobre la producción y el acceso al recurso. Las tensiones se incrementarán por las disputas que generan los usos consuntivos y no consuntivos del recurso hídrico, especialmente cuando el agua escasea ${ }^{4}$.

A lo largo de la cuenca, por lo tanto, la gobernanza sobre manejo y distribución del recurso hídrico será vital para abordar la complejidad que generan los distintos usos del recurso. El rol de los distintos gobiernos locales que tienen territorios sobre la cuenca en gobernar el acceso y distribución del agua es imprescindible. De igual manera, la promulgación y el cumplimiento de leyes de agua nacionales que ordenen los distintos usos del recurso, dados los diferentes intereses contrapuestos que están en juego, serán críticos. En las ciudades ubicadas a lo largo de los ríos, el manejo y acceso al recurso se volverá un tema de eficiencia y eficacia para que no se desperdicie el recurso y para que la población, indistintamente de su condición socioeconómica y lugar de habitación, tenga acceso en condiciones de equidad. Si no se logra esta eficiencia en el uso del recurso, los conflictos se agudizarán a medida que las fuentes de agua se vuelvan exiguas.

4 «El uso consuntivo es la fracción de la demanda de agua que no retorna al medio hídrico después de su uso, sino que es consumida por las actividades mismas, descargada al mar o evaporada. El uso consuntivo se vincula al uso doméstico y municipal en zonas urbanas, industria y minería, regadío agrícola y ganadería. El uso no consuntivo se vincula a la demanda de agua que se devuelve al medio hídrico sin alteración significativa de su calidad. Incluye la generación hidroeléctrica, acuicultura, afluentes domésticos, retornos de riego y caudales medioambientales. El uso no consuntivo condiciona y limita el suministro de los usos consuntivos, pues debe estar disponible en el tiempo y en el espacio y con la calidad apropiada. Se calcula que entre $70 \%$ y $80 \%$ del agua se utiliza en agricultura» (véase: http://www.uach.cl/proforma/insitu/2_insitu.pdf). 
Finalmente, un tema importante en la conservación de la cuenca y que podría minimizar las tensiones generadas por la disminución de la cobertura vegetal es el enfoque que la cooperación internacional y los gobiernos nacionales en ALC den a sus proyectos para que a los campesinos pobres que viven y trabajan a lo largo de la cuenca se les pague por la conservación de los servicios ecosistémicos ambientales. Hoy muchos proyectos se enfocan demasiado en servicios globales que buscan mitigar las causas del cambio climático u otros problemas ambientales (por ejemplo, la producción de oxígeno, purificación del agua, protección de inundaciones, formación de suelos y nutrientes, regulación del clima, entre otros). Para que sean efectivos, los proyectos deberían pagar por aquellos bienes ambientales que realmente son aprovechados por la población y tienen impacto local, ya que proporcionan los medios de vida para las comunidades (por ejemplo: agua dulce, madera, alimentos y leña).

\section{III.4. Desiguales capacidades de adaptación frente al cambio climático}

Las estrategias para enfrentar el impacto del calentamiento global tienen alcances desiguales y ayudan a entender el posible vínculo entre cambio climático, conflicto y seguridad. En la conferencia mundial celebrada en 2009 en Copenhague, Dinamarca, se acordó que la reducción de la emisión de GEI y/o evitar su producción no eran suficientes para enfrentar el problema. Se requerían, paralelamente, acciones encaminadas a reducir la vulnerabilidad de los países pobres y más proclives a experimentar los efectos del cambio climático y construir en ellos mayor resiliencia para enfrentar estos fenómenos (UNFCCC 2010).

La resiliencia indica la capacidad de adaptar y mantener las funciones esenciales frente a las amenazas, los riesgos y sus efectos, especialmente de poblaciones vulnerables. Por lo general, requiere una capacidad de anticipar el cambio climático y planificar las adaptaciones necesarias para ello (Satterthwaite et al. 2007). La resiliencia de un ente a la variabilidad climática interactúa con su capacidad de resistencia frente a otras presiones dinámicas, como el cambio económico, el conflicto y la violencia. Dicha capacidad adaptativa no se da solamente en función de la situación financiera y económica de cada país, sino de otros factores, incluyendo la capacidad institucional y técnica, la existencia de infraestructura apropiada y el manejo seguro de sus recursos naturales (CAF 2014), así como la sensación de pertenencia a un lugar por sus habitantes (Fresque-Baxter y Armitage 2012).

Las estrategias de adaptación son también contenciosas, pues requieren una discusión en torno a la naturaleza y la temporalidad de las amenazas derivadas del cambio climático (Thomalla et al. 2006). ¿El cambio climático implica un incremento en la magnitud y frecuencia de eventos climatológicos extremos de corta duración que producen shocks de tal amplitud que afectarían a millones de personas (Sperling y Szekely 2005)? ¿O implican modificaciones más lentas, paulatinas e imperceptibles en las cuales la variabilidad y la intensidad de los cambios son menos dramáticas (Hellmuth et al. 2007; Moser et al. 2010)? Si son cambios menos dramáticos, los conflictos generados podrían ser de naturaleza distinta a aquellos provocados por grandes huracanes, 
inundaciones o sequías catastróficas, y requerirían de otro tipo de estrategias de adaptación para minimizar la conflictividad.

Analizando el caso de dos ciudades costeras del Caribe mexicano (Mahahual y Playa del Carmen) que sufren los impactos del cambio climático por huracanes, ondas de calor e incremento en el nivel del mar, Pelling y Navarrete (2011) concluyen que la capacidad de adaptación está íntimamente vinculada a relaciones sociales de poder, y que las contradicciones que mantienen o transforman estas relaciones son las que pueden eventualmente incrementar o limitar la capacidad de resiliencia de familias de escasos recursos y minimizar cierto nivel de conflictividad.

\section{CAMBIO CLIMÁTICO, DESIGUALDADES Y CONFLICTIVIDAD URBANA}

A partir de 2008, más del 50\% de la población mundial vive en zonas urbanas. En los próximos años, el principal crecimiento poblacional sucederá en ciudades, no solo por efecto de migraciones internas y transnacionales, sino sobre todo por el crecimiento vegetativo propio. En algunos países de ALC más del $70 \%$ de la población ya vive en ciudades. En 2010, en todos los países de Centroamérica, incluyendo Panamá y Belice, más del 50\% de su población vivía en zonas urbanas (UNFPA 2007).

Actualmente, el $75 \%$ del total de la población urbana en países de ingresos bajos o medio-bajos vive en zonas de alto riesgo a los impactos de fenómenos asociados con el cambio climático. La totalidad del crecimiento poblacional mundial en los próximos años ocurrirá en estas ciudades, y es en ellas donde se encuentran los grupos más vulnerables a riesgos asociados con el cambio climático (Bicknell, Dodman y Satterthwaite 2007). No es casual que la mayoría de muertes debido a tormentas tropicales y ciclones suceda en países de ingresos bajos, mientras que la mayoría de pérdidas económicas por estos fenómenos ocurre en países de renta alta (Johnson 2010).

Según un informe de la Corporación Andina de Fomento (CAF), el 48\% de las capitales de ALC presentan una alta vulnerabilidad al cambio climático. Ninguna de las capitales de los 33 países tiene una categoría de bajo riesgo de vulnerabilidad, lo cual es preocupante dado al rol que juegan estas urbes en los procesos de gobernanza nacional y su contribución a la economía de cada país (CAF 2014). En Centroamérica, con la excepción de Costa Rica y Panamá, más del 30\% de la población urbana vivía en asentamientos informales y precarios (United Nations Population Division 2007), la mayoría altamente vulnerables a dichos riesgos (Lavell 2000; Wamsler 2007).

Paradójicamente, las estrategias nacionales de adaptación en la mayoría de países de ALC en sus orígenes poseen un enfoque rural vinculado al manejo y gestión de recursos naturales renovables. Es más, la rectoría de dichas estrategias ha recaído en los ministerios del ambiente y recursos naturales, y cuando abordan la adaptación al cambio climático a nivel urbano, lo hacen bajo la óptica del manejo y gestión de riesgos ante grandes desastres y catástrofes asociadas al cambio climático (Moser et al. 2010).

Si bien los grandes «desastres» resaltan la urgencia e importancia para abordar el cambio climático a nivel urbano, estudios en las ciudades de Estelí, Nicaragua; Cartagena, Colombia, y Tegucigalpa, Honduras, muestran por qué este enfoque impide ver 
cómo fenómenos de clima severo, pero no extremo, afectan a los asentamientos informales y exacerban una serie de condiciones ambientales que pudieran provocar mayores conflictos locales (véase: Moser y Stein 2011; Stein y Moser 2014). Este enfoque impide ver las estrategias de adaptación que los hogares, los pequeños negocios y las comunidades están desarrollando para enfrentar los efectos de dichos fenómenos, las cuales en la mayoría de casos son ignoradas por las autoridades municipales y también por grupos de poder a nivel local (Stein y Moser 2014).

Una manera de entender la relación cambio climático y conflicto en contextos urbanos es la sugerida por Moser y Rodgers (2012:3) para rastrear procesos sociales que llevan a una transición potencial desde el conflicto a la violencia, viendo cómo estos se generalizan en vez de mantenerse específicos y lo hacen de manera rápida y súbita en vez de gradual. Para ello sugieren rastrear «cómo interactúan entre sí diferentes formas de conflicto y violencia generados por procesos de puntos de inflexión en un efecto dominó», analizando la cadena de causalidad existente entre diferentes tipos de conflicto o violencia que se dan, el contexto en que se dan y los procesos a través de los cuales se articulan entre sí (Moser y Rodgers 2012). Dado que los espacios urbanos tienen dinámicas particulares que pueden exacerbar el conflicto y provocar fácilmente que este se expanda de una comunidad a nivel de la ciudad, es importante conocer cómo fenómenos climáticos severos y extremos afectan a determinados asentamientos urbanos.

A continuación, se presentan dos casos que ejemplifican cómo fenómenos de clima severo afectaron los asentamientos informales en dos conurbanos de ALC y exacerbaron conflictos de diversa índole. El primero se refiere a un desastre ocurrido en Ciudad de Guatemala, en octubre de 2015, y el segundo, a un barrio ubicado en la ciudad de Cartagena, Colombia, que por décadas enfrenta los impactos de variaciones climáticas severas.

\section{IV.1. Lluvias, desigualdad y conflictividad territorial: El Cambray II, Guatemala}

Al igual que otras capitales latinoamericanas, Ciudad de Guatemala ha experimentado durante las últimas décadas un crecimiento poblacional y una expansión territorial acelerados. En el Área Metropolitana de Guatemala (AMG), compuesta por 13 municipios -incluyendo el municipio de Guatemala-, viven más de 5 millones de habitantes. Esta rápida conurbación tiene implicaciones en la calidad de vida de sus habitantes, agudizando problemas de acceso a vivienda, servicios y equipamiento urbano, al igual que un acelerado deterioro ambiental y aumento en los niveles de pobreza, exclusión social y violencia urbana (Vettorazi 2015). Su acelerado crecimiento convirtió el AMG en una región altamente vulnerable a amenazas socionaturales, pues se ubica en una zona de alto riesgo de fenómenos sísmicos, volcánicos e hidrogeológicos, con problemas de erosión de suelos, deslizamientos e inundaciones. Esta precaria situación, combinada con ciertos modelos de desarrollo urbano impulsados durante las últimas décadas, generó una dualidad marcada por la selectividad territorial (ASIES 2003).

Hace cincuenta años El Cambray era una finca privada situada a los pies de un barranco en la municipalidad de Santa Catarina Pinula, colindante con la municipalidad 
de Guatemala. Los primeros pobladores de El Cambray se asentaron en un caserío que luego empezó a fraccionarse en lotes en los cuales se ubicaron familiares que carecían de vivienda y servicios básicos. A partir de 2008, funcionarios municipales empezaron a persuadir a residentes de El Cambray de reubicarse en otras áreas, debido a preocupaciones que existían sobre posibles deslizamientos de las colinas circundantes. En noviembre de 2014, la Coordinadora Nacional para la Reducción de Desastres (CONRED) instó a los residentes a reubicarse «inmediatamente» para evitar cualquier desastre. El 1 de octubre de 2015 por la noche se desplomó el cerro aledaño, provocando la muerte de 280 personas, 70 desaparecidos y la destrucción de cientos de viviendas (El Periódico 2/10/15). El evento fue precedido por días de intensas precipitaciones en la época lluviosa, que ya habían causado moderadas inundaciones, deslizamientos de tierra y dos muertes en otras áreas del país.

La ausencia de ordenamiento territorial, la falta de normas de urbanización y el carácter no vinculante de los dictámenes de la CONRED fueron señalados como parte de las causas que llevaron a la tragedia. Precisamente, la catástrofe asociada a un evento climático permitió identificar una serie de conflictos implícitos derivados de este tipo de desastres.

\section{IV.1.1. Conflictos interinstitucionales}

El desastre ejemplificó cómo la falta de políticas de regulación y ordenamiento territorial genera conflictos de carácter institucional. CONRED había alertado sobre la condición del lugar desde 2008, lo cual fue negado por el alcalde Albarizáez, quien «desconocía si la CONRED entregó a la comuna algún informe acerca de la situación de la colonia afectada específicamente, aunque reconoció que años atrás ocurrió un deslave similar»s. Por su parte, el exalcalde de Santa Catarina, Antonio Coro, quien dirigió la comuna por cuatro periodos, escribió un libro acerca del conflicto limítrofe con el municipio de Guatemala. Coro argumenta que El Cambray está ubicado en un área en disputa, y ninguna de las dos comunas se hace responsable del otorgamiento de licencias de construcción. Indicó que el Instituto Geográfico Nacional publicó en 1991 el límite municipal entre Santa Catarina y la ciudad capital, el cual fue ratificado en 2006 por el Ministerio de Gobernación. Resaltó que la comuna «no está de acuerdo con el trazo porque según la medición se perderían 69 hectáreas» (República.gt 9/10/15).

Los efectos del conflicto territorial tienen implicaciones para prevenir este tipo de tragedias. «En caso de producirse alguna amenaza que ponga en riesgo la seguridad de personas o sus bienes, la CONRED, en colaboración con las Coordinadores Regionales, Departamentales, Municipales o Locales para la Reducción de Desastres, deberá evacuar a un lugar seguro a las personas que se encuentren en riesgo en el área indicada en

5 Disponible en: https://www.prensalibre.com/guatemala/comunitario/autoridades-dan-detallesde-lo-ocurrido-en-cambrey. 
este acuerdo, por lo que para el efecto debe aunar esfuerzos con las municipalidades correspondientes» (República.gt 9/10/15). Fue evidente que esto no sucedió.

El crecimiento demográfico ha provocado que la Ciudad de Guatemala deje de tener límites urbanos administrativos claros (Vetorazzi 2015). La falta de entendimiento se ve reflejada en el conflicto territorial e institucional entre Santa Catarina Pinula y la Ciudad de Guatemala y, por ende, en la planificación y prevención de riesgos, lo cual ha agravado la situación de vulnerabilidad de sus habitantes ante los impactos del cambio climático.

\section{IV.1.2. Conflictos ideológicos}

Berganza (2015) atribuye a los procesos de desregularización y privatización como instrumentales en limitar la capacidad del Estado para realizar una gestión integral de riesgos. Velázquez (2010: 12) destaca que la expansión urbana de Guatemala ha sido acompañada de un proceso de «mercantilización masiva del suelo urbano y dinamización del mercado inmobiliario a partir de una fuerte demanda habitacional, lo cual ha impedido al Estado regular el uso del suelo». Aunque la producción de tierra por agentes privados en el AMG se haya dado de forma formal o regulada, en muchos casos las lotificaciones no cumplen con la regulación urbanística que aseguraría su calidad y seguridad (Samayoa 2007:15).

Dentro de este margen de permisividad del Estado, incluyendo los gobiernos municipales, han surgido «lotificaciones fantasmas», que ni siquiera obtienen licencias de construcción (Samayoa 2007). La precaria institucionalidad no tiene medios para impedir la formación de nuevos asentamientos irregulares y construir obras de mitigación, o para reubicar a cientos de familias en riesgo. Las municipalidades continúan autorizando proyectos urbanísticos sin estudios de riesgo o medidas de mitigación, siguiendo el modelo actual de desarrollo urbano donde prima el interés privado sobre lo público. Así, el modelo neoliberal en Guatemala no solo limita la función reguladora del Estado, sino que obliga a pobladores de escasos recursos a vivir en zonas de alto riesgo que les son asequibles económicamente.

\section{IV.1.3. Conflictos socioeconómicos}

Las tierras que habitaban los pobladores de El Cambray presentaban altos grados de exposición a amenazas, y las decisiones de los pobladores para asumir dicho riesgo fueron complejas. Según Luhmann (1991), el riesgo es un concepto opuesto a la noción de seguridad, de manera que su ponderación es «variable, subjetiva, coyuntural y dependiente de otros problemas que puedan priorizarse como el alimento, una enferme$\mathrm{dad}$, o cualquier otro problema inmediato como la violencia». Utilizando este marco de riesgo, Berganza (2015) justifica que era poco realista esperar que quienes vivían en El Cambray actuaran de acuerdo a la lógica formal institucional de la percepción del riesgo, ya que dicha percepción no era lo suficientemente intensa antes del deslizamiento 
como para atender las advertencias institucionales. Desde el ámbito institucional no hubo información, ni el diseño de un plan alternativo para resolver su condición de riesgo. El plan simplemente no existió, porque las instituciones no tenían ni el mandato, ni la estructura humana, ni los recursos para tal efecto.

Días después de la tragedia, muchas familias accedieron a evacuar sus casas y reubicarse en albergues temporales, con la expectativa de una respuesta oficial. Pero el motivo de su decisión no fue ningún estudio de riesgo, sino la tragedia misma. Las personas en zonas de alto riesgo pueden tomar decisiones informadas para proteger su integridad física, pero muchas veces están condicionadas por factores económicos y diversas formas de exclusión. Para reducir el riesgo, los habitantes de El Cambray interactuaban con instituciones que no ofrecieron soluciones viables.

El gobierno de Guatemala decidió reubicar a las familias de El Cambray en un proyecto habitacional en San José Pinula, otro de los 13 municipios de la AMG. Sin embargo, el proyecto fue rechazado por las autoridades municipales de San José Pinula y por grupos de altos ingresos económicos, aduciendo que el proyecto atentaba contra uno de los pulmones verdes de la capital. Visiblemente molesto, el presidente respondió que si bien «el Estado tomaría todas las disposiciones para que no haya daños a la ecología, el medio ambiente y la seguridad de los habitantes de San José Pinula», la discriminación «va en contra de la Constitución, los derechos humanos y las convenciones internacionales que garantizan la igualdad y que el proyecto habitacional no se detendría» (La Hora 2015).

En resumen, El Cambray mostró cómo los impactos de un fenómeno climático extremo sacaron a relucir distintos tipos de conflictividad, en un contexto de expansión y crecimiento urbano acelerados, donde no ha habido claridad institucional sobre la delimitación de funciones sobre el manejo y regulación del uso del suelo y la gestión de riesgo, lo que ha exacerbado aún más los procesos de exclusión social y discriminación económica.

\section{IV.2. Barrio Policarpa: Cartagena, Colombia ${ }^{6}$}

Cartagena de Indias es el puerto más importante de Colombia en el Caribe. Con más de un millón de habitantes, la ciudad muestra patrones claros de segregación espacial, aumento en los niveles de pobreza y desigualdad. Durante décadas la ciudad ha experimentado un incremento gradual en las temperaturas promedio anuales y un aumento en el nivel del mar causado por altas mareas, vientos fuertes y recurrentes inundaciones. Las precipitaciones anuales promedio se han incrementado en 78 milímetros por década, el doble de lo que ocurre en otras ciudades del Caribe colombiano, lo que ha provocado problemas en distintas zonas de la ciudad, especialmente en barrios de escasos recursos. 2011)

6 La información se basa en un estudio de planificación de adaptación de activos (UTB/GURC 
En 2011, el barrio tenía 7.200 habitantes ubicados en 972 viviendas. La topografía del terreno es plana y el barrio está cortado por dos canales por los cuales escurren las aguas de lluvias. Dada la proximidad a la bahía de Cartagena, los terrenos del barrio son cenagosos. Estudios técnicos de la municipalidad de Cartagena muestran que el barrio sufre impactos de riesgos ambientales y tecnológicos no mitigables, y por ello la inclusión del barrio en el plan de inversiones de la municipalidad se vuelve legalmente casi imposible, lo cual impide invertir recursos fiscales para construir obras de infraestructura que harían el asentamiento menos vulnerable a riesgos climáticos. A pesar de que hay familias que viven por más de tres décadas y que no tienen interés en ser reubicadas, la alcaldía traspasa de administración a administración la problemática legal y ambiental del barrio. A la fecha del estudio solo una familia poseía escritura de propiedad.

Los habitantes del barrio son críticos con las grandes empresas aledañas que han causado, según ellos, «el problema de las inundaciones y no han aportado a la construcción de buenos canales para el desagüe». Indican que los malos olores que prevalecen en el barrio son consecuencia de las emanaciones de las empresas; y el olor es tan fuerte que les quita el apetito a la hora de comer y ha provocado diarreas y náuseas. «Mientras las empresas estén, no es mucho lo que se puede hacer con el mal olor» $\mathrm{y}$ «quejarse con ellas es pelea de tigre con burro amarrado». También mencionan que en la zona sur del barrio los vecinos han realizado rellenos para adecuar sus lotes, lo cual ha alterado el cauce en épocas de lluvias, impidiendo ampliar el canal, además de que allí botan la basura por falta de servicios de aseo.

Parte de los pobladores son desplazados internos del conflicto armado, lo que muestra una situación inversa: una situación de conflicto agrava la capacidad adaptativa de grupos poblacionales ante fenómenos climáticos. Colombia es el país de ALC con mayor población interna desplazada debido al conflicto armado y la pérdida de sus medios de vida los ha obligado muchas veces a ubicarse en asentamientos marginales más expuestos a fenómenos climatológicos como lluvias, inundaciones y sequías.

En 2010, las inundaciones provocaron derrames de aceite de empresas aledañas, lo cual afectó la salud de los habitantes del barrio. Varias veces los pobladores del barrio han tomado la principal carretera que une la zona industrial con la ciudad para demandar que la municipalidad reconozca sus derechos de tenencia de la tierra; que se inicie un proceso de titulación y se ponga fin a los problemas ambientales que se generan debido a los problemas de inundación y contaminación de las industrias aledañas. Algunos pobladores mencionan que a las empresas les interesa la tierra que actualmente ocupa el barrio y que no sería extraño que los problemas ambientales, agravados con la intensidad y frecuencia creciente de los vientos y las lluvias, se utilicen como pretextos para reforzar el argumento de que las familias deben ser reubicadas en otras áreas. La falta de cohesión social para enfrentar estos problemas también repercute en los niveles de conflictividad al interior del barrio, así como entre los habitantes y las autoridades distritales. 
ALFREDO STEIN

CAMBIO CLIMÁTICO Y CONFLICTIVIDAD SOCIOAMBIENTAL

EN AMÉRICA LATINA Y EL CARIBE

\section{REFLEXIONES Finales}

Si bien la comunidad científica permanece dividida respecto a la asociación posible entre cambio climático y conflicto, estudios recientes han encontrado correlaciones entre distintos eventos climáticos extremos severos (por ejemplo, alzas de temperaturas, sequías prolongadas e incremento de las precipitaciones) y cierto tipo de conflictos e inclusive de violencia interpersonal y grupal. Sin embargo, el debate sobre la causalidad no se ha zanjado. Hay investigadores que argumentan que la evidencia es todavía inconclusa y que faltan más estudios de caso que prueben cuantitativa y cualitativamente dicha relación. Hay quienes alertan sobre las consecuencias de sobredimensionar las amenazas para la seguridad mundial que estos conflictos de «baja intensidad» impliquen, ya que podrían conllevar soluciones militares para prevenir las migraciones masivas transnacionales o para asegurar el acceso a recursos escasos tales como agua, alimentos y otros recursos naturales.

Dada la incertidumbre en las predicciones futuras de cambios en la intensidad y frecuencia de fenómenos de clima asociados al cambio climático, la posibilidad de anticipar los impactos que la variabilidad climática pueda tener en ALC en su conjunto se vuelve compleja. No obstante, en las últimas cinco décadas se decantan ciertas tendencias que podrían mostrar los patrones futuros de estos cambios, que afectarán a la región en su conjunto: mayores e intensos, pero cortos periodos de precipitaciones acompañadas de sequías prolongadas. Dada la heterogeneidad de ecorregiones del continente, los impactos deben analizarse a nivel de distintas subregiones y, sobre todo, al interior de cada país, tanto en áreas urbanas como rurales.

Las tensiones que se generarán por los diversos usos del agua y la forma en que diferentes intereses y grupos sociales tengan acceso a ella, pero sobre todo cómo se manejen los recursos hídricos, serán claves para entender los conflictos futuros entre países, al interior de diversos países, así como entre regiones rurales y urbanas. Tal como hemos visto en este documento y en el Anexo I ${ }^{7}$, en el contexto del cambio climático el agua no solo representa un riesgo por las potenciales inundaciones pluviales y fluviales que produce, sino que, al ser un recurso escaso y finito, si no se maneja con equidad y destinado a satisfacer ante todo las necesidades crecientes de la población pobre urbana y rural, en época de sequías prolongadas podría ser detonante de agudos conflictos sociales y políticos. Por ello, la gobernanza transnacional, nacional y municipal sobre el recurso es fundamental para evitar conflictos, tal como sucede en el caso del manejo de las cuencas de los ríos y la reducción de la cobertura vegetal, tan necesaria para reducir inundaciones y garantizar la generación del recurso. Los impactos dependerán de la vulnerabilidad de distintos grupos sociales, la cual se verá magnificada a medida que sus recursos sean más sensibles, estén más expuestos y tengan menor capacidad de adaptación a estos fenómenos.

7 El Anexo I presenta varios conflictos ambientales derivados de aquellos que sufren los impactos del cambio climático, pero también los que sufren las consecuencias de esfuerzos por reducir la emisión de GEI. 
Siendo una de las regiones que han contribuido relativamente poco a generar el calentamiento global, resulta paradójico que ALC sea también una de las regiones más impactadas y que posiblemente sufrirán más los efectos de los cambios climáticos futuros. La razón para ello tiene que ver con sus altos índices de pobreza, pero sobre todo con la exclusión y las desigualdades socioeconómicas provocadas por las políticas neoliberales de desregularización y privatización en las últimas décadas, no solo porque la región sea ya la más urbanizada del planeta, sino porque las estructuras institucionales de poder -tanto públicas como privadas- que existen en la mayoría de países producen y reproducen estas desigualdades, e impiden que los costos del impacto de los fenómenos climáticos sean distribuidos equitativamente y que las soluciones técnicas y financieras de adaptación sean accesibles para todos sin exclusión alguna. Lo preocupante de esta dinámica es que las desigualdades de poder existentes sean incapaces de proveer las soluciones requeridas para que amplios sectores de la población fortalezcan su capacidad de resiliencia ante fenómenos climáticos extremos y severos. Precisamente, la falta de respuestas institucionalizadas podría conducir inexorablemente a una mayor sensación de abandono, impotencia y frustración, y que ello desemboque en protestas y conflictos que no puedan ser contenidos y deriven inclusive en violencia.

A manera de resumen, la Tabla II los describe.

\section{TABLA II}

RAÍCES Y TIPOS DE CONFLICTOS ACTUALES Y FUTUROS

\begin{tabular}{l|l}
\hline RAÍZ DE LOS CONFLICTOS & \multicolumn{1}{|c}{ TIPO DE CONFLICTOS ACTUALES Y FUTUROS } \\
\hline $\begin{array}{l}\text { Desigualdades asociadas } \\
\text { con causas del cambio } \\
\text { climático. }\end{array}$ & $\begin{array}{l}\text { Tensiones en foros internacionales entre países desarrollados y en } \\
\text { vías de desarrollo. Se generarán bloques de países antagónicos y al } \\
\text { interior de ciertos países como elementos aglutinantes de unidad } \\
\text { nacional. }\end{array}$ \\
\hline $\begin{array}{l}\text { Desigualdades asociadas } \\
\text { con impactos del cambio } \\
\text { climático. }\end{array}$ & $\begin{array}{l}\text { Los países que sufrirán el mayor impacto de fenómenos asociados } \\
\text { al cambio climático incrementarán sus demandas sobre países que } \\
\text { históricamente han contribuido a la generación de los GEI. Algunos } \\
\text { conflictos asociados al recurso hídrico podrían agudizarse, } \\
\text { especialmente en cuencas y acuíferos transfronterizos. }\end{array}$ \\
\hline $\begin{array}{l}\text { Desigualdades en las } \\
\text { capacidades de responder } \\
\text { a impactos del cambio } \\
\text { climático. }\end{array}$ & $\begin{array}{l}\text { Posiblemente las que generen mayor nivel de tensión y } \\
\text { conflictividad social a lo largo de ALC, pues harán evidentes y } \\
\text { transparentes las profundas inequidades existentes entre el campo } \\
\text { y la ciudad, así como al interior de las ciudades, y cómo factores } \\
\text { tales como el acceso al suelo urbano y la infraestructura para } \\
\text { enfrentar los riesgos de inundaciones y deslizamientos, al igual que } \\
\text { las ondas de calor y la falta de agua, tienen que ver con deudas } \\
\text { sociales no atendidas. }\end{array}$ \\
\hline
\end{tabular}


ALFREDO STEIN

CAMBIO CLIMÁTICO Y CONFLICTIVIDAD SOCIOAMBIENTAL

EN AMÉRICA LATINA Y EL CARIBE

\begin{tabular}{l|l}
\hline RAÍZ DE LOS CONFLICTOS & \multicolumn{1}{|c}{ TIPO DE CONFLICTOS ACTUALES Y FUTUROS } \\
\hline $\begin{array}{l}\text { Desigualdades sobre } \\
\text { quiénes deberían asumir } \\
\text { los costos de prevenir el } \\
\text { cambio climático. }\end{array}$ & $\begin{array}{l}\text { Conflictividad entre países desarrollados y en vías de desarrollo. } \\
\text { Ya se decantan algunos casos donde la generación de energías } \\
\text { renovables (por ejemplo, eólicas e hidroeléctricas) y el pago por } \\
\text { servicios ecosistémicos no den los resultados sociales esperados } \\
\text { en comunidades locales e incrementen la violencia contra líderes } \\
\text { opositores. }\end{array}$ \\
\hline $\begin{array}{l}\text { Desigualdades sobre } \\
\text { quiénes deberían asumir } \\
\text { los costos de adaptación } \\
\text { al cambio climático. }\end{array}$ & $\begin{array}{l}\text { Causará tensiones entre países desarrollados y en vías } \\
\text { de desarrollo, así como al interior de países de ALC. Las } \\
\text { reivindicaciones sociales sobre los costos de adaptación se } \\
\text { incrementarán, especialmente por sectores que sufren los mayores } \\
\text { impactos. }\end{array}$ \\
\hline
\end{tabular}

Fuente: Elaboración propia.

\section{BIBLIOGRAFÍA}

Agnew, Clive y Woodhouse, Philip. Water Resources and Development. New York: Routledge, 2011.

ASIES. Asociación DE InVEstigación y Estudios Sociales. Asentamientos precarios en la ciudad de Guatemala. Momento, 2003, n. ${ }^{\circ}$ 6: 1-10.

BID. BANCO InTERAmeriCANo De DeSARROllo. Indicadores de Riesgo de Desastre y de Gestión de Riesgos. Notas Técnicas IDB-TN-169. Washington D. C.: BID, 2010.

BARNeTt, Jon y ADGER, Neil. Climate change, human security and violent conflict. Political Geography, 2007, vol. 26: 639-655.

BARRETT, Oliver-Leighton. Top Climate Security Implications for Latin America: A regional breakdown. Centre for Climate and Security: Washington D. C., 2014.

Berganza, Ricardo. Por qué El Cambray II no es sólo culpa del Estado. Plaza Pública, 16 de octubre de 2015, en línea: http://www.plazapublica.com.gt/content/ por-que-el-cambray-ii-no-es-solo-culpa-del-estado.

BERnAUER, Thomas; BÖHMLET, Tobias y KOUBI, Vally. Environmental changes and violent conflict. Environmental Research Letters, 2012, vol. 7 (1), en línea: http://iopscience.iop.org/ article/10.1088/1748-9326/7/1/015601/pdf.

Bicknell, Jane; Dodman, David y Satterthwaite, David (eds.). Adapting Cities to Climate Change: Understanding and Addressing the Development Challenges. London: Earthscan, 2007.

Brunnengräber, Achim. Clima, política de cambio climático y caballos muertos. Por qué la protesta rutinaria no es suficiente. Revista Nueva Sociedad, 2014, vol. 252: 130-135.

BuRKE, Marshall; Hsiang, M. Solomon y Miguel, Edward. Climate and Conflict. NBER Working Paper 20958. Cambridge: National Bureau of Economic Research Working Paper Series, 2014.

CAF. BANCO DE DeSARROLlo de AmÉRICA LATINA. Índice de vulnerabilidad y adaptación al cambio climático en la región de América Latina y el Caribe. Corporación Andina de Fomento (CAF), Banco de Desarrollo de América Latina, 2014.

Calderón, G. F. (coord.). La Protesta Social en América Latina. Cuaderno de Prospectiva Política 1. Buenos Aires: Siglo XXI, 2012. 
ALFREDO STEIN

CAMBIO CLIMÁTICO Y CONFLICTIVIDAD SOCIOAMBIENTAL

EN AMÉRICA LATINA Y EL CARIBE

CEPAl. COMISIÓN ECONÓMICA PARA AmÉRICA LATINA y el CARIBe. La economía del cambio climático en Centroamérica, Síntesis 2010. Convenio entre el Ministerio Británico para el Desarrollo Internacional (DFID) y la Sede Subregional en México de la Comisión Económica para América Latina y el Caribe (CEPAL), dentro del Proyecto «La economía del cambio climático en Centroamérica». México.

Chaplin, Ann. Percepciones de comunarios y comunarias del Altiplano Boliviano sobre los cambios en el clima y sus efectos. La Paz: Creart Impresores, 2009.

Cosso, Melina. El Acuífero Guaraní como Recurso Vital y Estratégico, en el marco de la Defensa Nacional, 2011, en línea: http://www.ina.gov.ar/pdf/ifrrhh/01_024_Cosso.pdf.

Dodman, David. Climate Change and Cities: Impacts, Inequalities and Responses. Presentación en el curso Critical Issues in Urban Inequalities. Manchester, Reino Unido, 2 de diciembre de 2015.

El PERIÓDICO. Conred: 600 desaparecidos, nueve muertos, 34 heridos y 65 refugiados por tragedia en el Cambray II, 2 de octubre de 2015, en línea: http://web.archive.org/web/20151002220635/ http://elperiodico.com.gt/2015/10/02/pais/conred-600-desaparecidos-nueve-muertos34-heridos-y-65-refugiados-por-tragedia-en-el-cambray-ii/. Fecha de consulta: 21 de noviembre de 2015.

Environmental Justice Atlas. Baleia Wind Power Complex in Ceará, Brazil, en línea: https:// ejatlas.org/conflict/baleia-wind-power-complex-in-ceara-brasil. Fecha de consulta: 21 de marzo de 2016.

EnVironmental Justice Atlas. Wind Farms in the Sustainable Development Reserve of Ponta do Tubarão, Brazil, en línea: https://ejatlas.org/conflict/wind-farms-in-the-sustainable-development-reserve-of-ponta-do-tubarao-brasil. Fecha de consulta: 21 de marzo de 2016.

Equipo TÉCNICO DE EMERGENCIAS DE LAS NACIONES UnIDAS. UNETE. Guatemala: Sequí por Canícula Prolongada 2014. Reporte de la Oficina del Coordinador Residente, 2014, en línea: http://reliefweb.int/sites/reliefweb.int/files/resources/Redhum_GT_Informe_de_Situacion_No_1_Sequia_UN-20140904-IC-15403.pdf. Fecha de consulta: 22 de febrero de 2016.

FERNÁNDEZ-JAUREGUI, Carlos. El agua como fuente de conflictos: repaso de los focos de conflictos en el mundo. Afers Internationals, 1999, vols. 45-46: 179-194.

Francisco I. Carta Encíclica Laudato Si' del Santo Padre Francisco sobre la ciudad y el cuidado de la casa común. Roma: Tipografía Vaticana, 2015.

FresQue-BAXTeR, Armitage D. Place identity and climate change adaptation: a synthesis and framework for understanding. WIREs Climate Change, 2012, vol. 3: 251-266.

Gardner-Outlaw, Tom y Engleman, Robert. Sustaining water, easing scarcity: A second update. Washington, D. C.: Population Action International, 1997.

Hellmuth, Molly; Moorhead, Anne; Thomson, Madeleine y Williams, Jim. Climate Risk Management in Africa: Learning from Practice. New York: The International Research Institute for Climate and Society, 2007.

Hertel, Thomas W.; Burke, Marshall B. y Lobell, David B. The poverty implications of climate-induced crop yield changes by 2030. Global Environmental Change, 2010, vol. 20: 577-585.

Hoffman, Max y Grigera Ana. Cambio Climático, Migración y Conflicto en la Amazonía y en los Andes. El Aumento de Tensiones y las Opciones de Políticas Públicas en Sudamérica. Washington D. C.: Center for American Progress, 2013.

IBARRARÁN, María Eugenia. Climate's Long-term Impacts on Mexico's City Urban Infrastructure. Cities and Climate Change: Global Report on Human Settlements, 2011, en línea: http:// unhabitat.org/wp-content/uploads/2012/06/GRHS2011CaseStudyChapter04Mexico.pdf. 
IDR. Institute De Recherche POUR Le Développement. Corriente de Humboldt: el impacto del cambio climático en el ecosistema, 2015, en línea: https://es.ird.fr/la-investigacion/losproyectos-de-investigacion/corriente-de-humboldt-el-impacto-del-cambio-climatico-en-elecosistema. Fecha de consulta: 15 de noviembre de 2015.

IPCC. Intergovernmental Panel on Climate Change. Tercer Informe de Evaluación, Cambio Climático 2001. Ginebra: Panel Intergubernamental de Cambio Climático, 2001.

ipcc. Intergovernmental Panel on Climate Change. Cambio Climático 2007, Reporte de Sintesis, AR4. Ginebra: Panel Intergubernamental de Cambio Climático, 2007.

IPCC. Intergovernmental PANEL On Climate Change. Managing the Risks of Extreme Events and Disasters to Advance Climate Change Adaptation. A Special Report of Working Groups I and II of the Intergovernmental Panel on Climate Change. Cambridge/New York: Cambridge University Press, 2012.

Kelly, Collin; Mohtadi, Shahrzad; Cane, Mark; Seager, Richard y Kushnir, Yochanan. Climate change in the Fertile Crescent and implications of the recent Syrian drought. Proceedings of the National Academy of Science, 2015, vol. 112 (11): 3241-3246.

KREFT, Sönke; Eckstein, David; Junghans, Lisa; Kerestan, Candice y Hagen, Ursula. Índice de Riesgo Climático Global 2015. Bonn: Germanwatch e.V., 2014.

LA Hora. El Cambray II: Presidente lamenta rechazo a proyecto, 2015, en línea: https://cerigua. org/article/presidente-maldonado-aguirre-ratifica-reasentamien/.

LAVELL, Allan. Desastres durante una década: Lecciones y avances conceptuales y prácticos en América Latina (1990-1999). Anuario Político y Social de América Latina, 2000 vol. 3: 1-32, en línea: http://www.desenredando.org/public/articulos/1999/ddud/DesastresDuranteUnaDecada-1.0-sep-12-2001.pdf.

LuHmann, Niklas. Sociología del riesgo. Guadalajara: Universidad Iberoamericana/Universidad de Guadalajara, 1991.

Lumerman, Pablo; Psathakis, Jimena y OrTiz, María de los Ángeles. Los impactos del cambio climático sobre los conflictos socio-ambientales: diagnóstico y desafíos de la situación argentina. Bruxelles: Initiative for Peace Building, 2011.

Martínez, Adalberto; Castillo, Nadia y García-Cueto, Rafael. México ante el cambio climático: Evidencias, impactos, vulnerabilidad y adaptación. México: Greenpeace, 2010, en línea: http:// www.greenpeace.org/mexico/Global/mexico/report/2010/6/vulnerabilidad-mexico.pdf.

MOSER, Caroline. Understanding the tipping point of urban conflict: violence, cities and poverty reduction in the developing world. Working Paper Series, n. ${ }^{\circ}$ 2, Urban Tipping Point (UTP). Manchester: University of Manchester, 2012.

MOSER, Caroline y HoRN, Philipp. Understanding the tipping point of urban conflict: conceptual framework paper. Working Paper Series, n. ${ }^{\circ}$, Urban Tipping Point (UTP). Manchester: The University of Manchester, 2011.

Moser, Caroline; Norton, Andrew; Stein, Alfredo y Georgieva, Sophia. Pro-Poor Adaptation to Climate Change in Urban Centers: Case Studies of Vulnerability and Resilience in Kenya and Nicaragua. Report, n. ${ }^{\circ}$ 54947. Washington D. C.: World Bank, 2010.

Moser, Caroline y RODGERS, Dennis. Entendiendo el punto de inflexión del conflicto urbano: informe global de politicas. Working Paper Series n. ${ }^{\circ}$ 7a, Urban Tipping Point (UTP). Manchester: University of Manchester, 2012.

Moser, Caroline y STEIN, Alfredo. Implementing urban participatory climate change adaptation appraisals: a methodological guideline. Environment and Urbanization, 2011, vol. 23 (2): 463-485.

NoRDÅs, Ragnhild y GLEDITSCH, Nils. Climate change and conflict. Political Geography, 2007, vol. 26 (6): 627-638. 
Pelling, Mark y Manuel-NavarRete, David. From resilience to transformation: the adaptive cycle in two Mexican urban centres. Ecology and Society, 2011, vol. 16 (2): 11.

PlANELlES, Manuel. China e India rechazan un pacto del clima que les iguale a los países ricos. El País, 9 de diciembre de 2015, en línea: http://internacional.elpais.com/internacional/2015/12/08/actualidad/1449585117_634927.html.

pnud. Programa de las Naciones Unidas Para el DesarRollo. Tras las huellas del cambio climático en Bolivia. Estado del arte del conocimiento sobre adaptación al cambio climático Agua y seguridad alimentaria. La Paz: Proyecto Fortalecimiento de las Capacidades Nacionales de Sistematización del Conocimiento, Información y Difusión sobre el Cambio Climático en Bolivia, 2011, en línea: http://www.undp.org/content/dam/bolivia/docs/Tras-las-huellasdel-Cambio-Climatico-en-Bolivia.pdf.

Programa Estado de la Nación. Cuarto Informe Estado de la Región en Desarrollo Humano Sostenible 2011. San José: Programa Estado de la Nación, 2011.

REPÚBLICA. Qué bay detrás de la tragedia en el Cambray II, 9 de octubre de 2015, en línea: http:// www.republicagt.com/nacional/que-hay-detras-de-la-tragedia-en-el-cambray-ii/.

Reuveny, Rafael. Climate change-induced migration and violent conflict. Political Geography, 2007, vol. 26 (6): 656-673.

RodRIGUES DE BRITO, Rafaela. Securitizing Climate Change: Expectations and Concerns. ETH. Zurich: International Relations and Security Network, 2012.

SAmayoa, Andrés. Propuesta de renovación e integración urbana para el Sector de la 30 Calle «A» hasta la 32 Calle desde la Avenida Bolivar hasta la Séptima Avenida de la Zona 8. Edificios Multifuncionales Proyecto Transmetro Eje Vial CA-9 Sur Aguilar Batres y Bolivar. Guatemala: Universidad de San Carlos de Guatemala, 2007, en línea: http://biblioteca.usac.edu.gt/ tesis/02/02_1864.pdf.

Satterthwaite, David; HuQ, Saleemul; Pelling, Mark; ReID, Hanna y LanKaO-Romero, Patricia. Adapting to Climate Change in Urban Areas; The possibilities and constraints in low-and middleincome nations. Climate Change and Cities Series, Discussion Paper, $n^{\circ}{ }^{1}$. London: IIED, 2007.

SCHEFFRAN, Jürgen y BATTAGLINI, Antonella. Climate and conflicts: the security risks of global warming. Regional Environmental Change, 2011, vol. 11 (Suppl. 1): 27-39.

SCHOCH, Corine. Rethinking climate change as a security threat. IIED Opinion, 2011 (October). London: IIED.

SeCretaría General de la Comunidad Andina. El Cambio Climático no tiene fronteras. Impacto del Cambio Climático en la Comunidad Andina. Perú: Ministerio de Medio Ambiente y Medio Rural y Marino, Agencia Española de Cooperación Internacional para el Desarrollo (AECID), 2008.

Smith, Paul J. Climate Change, Mass Migration and the Military Response. Orbis, 2007, vol. 51 (4): 617-633.

SNP. Sociedad Nacional de Pesquería. Asociaciones de Perú y Chile reafirman compromiso para intercambiar información pesquera, 15 de septiembre de 2015, en línea: http://www. perupesquero.org/en/tag/snp.

SPERLING, Frank y SzEKELY, Francisco. Disaster Risk Management in a Changing Climate. Discussion Paper prepared for the World Conference on Disaster Reduction on behalf of the Vulnerability and Adaptation Resource Group (VARG). Washington, D. C., 2005.

STEIN, Alfredo. Natural disasters, climate changes and environmental challenges in Central America. En SÁnChez-AnCocheA, Diego y Martí I Puig, Salvador (eds.). Handbook of Central American Governance. Abingdon/New York: Routledge International, 2014. 
ALFREDO STEIN

CAMBIO CLIMÁTICO Y CONFLICTIVIDAD SOCIOAMBIENTAL

EN AMÉRICA LATINA Y EL CARIBE

Swyngedouw, Erik y Heynen, Nikolas C. Urban Political Ecology, Justice and the Politics of Scale. Antipode, 2004, vol. 35 (5): 898-918.

Theisen, Ole Magnus; GLEDITSCH, Nils y BUHAUG, Halvard. Is climate change a driver of armed conflict? Climate Change, 2013, vol. 117 (3): 613-625.

ThOmalla, Frank; Downing, Tom; Spanger, Erika; GuOYI, Han y Rockstrom, Johan. Reducing hazard vulnerability: towards a common approach between disaster risk reduction and climate adaptation. Disasters, 2006, vol. 30 (1): 39-48.

un. United NATIONS. United Nations Security Council SC 9000. New York: Department of Public Information, News and Media Division, 2007, en línea: http://www.un.org/News/Press/ docs/2007/sc9000.doc.htm. Fecha de consulta: 23 de octubre de 2011.

un. United Nations. United Nations Security Council (SC/10332). New York: Department of Public Information, News and Media Division, 2011, en línea: http://www.un.org/News/ Press/docs/2011/sc10332.doc.htm. Fecha de consulta: 23 de octubre de 2011.

undP. United Nations Development Programme. Abrir espacios para la seguridad ciudadana y el desarrollo bumano: Informe sobre Desarrollo Humano para América Central idhac 2009-2010. Guatemala: Programa de las Naciones Unidas para el Desarrollo (PNUD), 2009, en línea: http://www.undp.org.gt/data/publicacion/IDHAC\%202009-2010.pdf. Fecha de consulta: 27 de noviembre de 2012.

unfCCC. United Nations Framework Convention on Climate Change. 52. ${ }^{\text {nd }}$ meeting of the CDM Executive Board. New York: United Nations, 2010.

United Nations Population Division. World Urbanization Prospects: The 2011 Revision. Department of Economic and Social Affairs, United Nations. New York: New York University, 2011.

utb/Gurc. Universidad Tecnológica de Bolívar y Global Urban Research Centre. Perfil de la Comunidad y Planificación de Activos, Proyecto Piloto en el Barrio Policarpa. Cartagena: AUPO-UTB Y GURC, 2011.

VAN JAARSVELD BRONKHORST, Salomé y Bob, Urmilla. Enviromental conflicts: Key issues and management implications. African Centre for the Constructive Resolutions of Disputes, 2010, en línea: http://www.accord.org.za/publications/.

Van Leeuwen, Mathijs y VAn Der HaAR, Gemma. Theorizing the Land-Violent Conflict Nexus. World Development, 2016, vol. 78: 94-104.

VetTorazI, Silvia. Mercado de Suelo Urbano en el Área Metropolitana de Guatemala. Universidad Rafael Landivar, CIESAS y CEMCA, 2015, en línea: https://drive.google.com/file/d/0B0VHw_mdbMHd0tFZ3dkYkw1cTA/view? usp=sharing. Fecha de consulta: 18 de noviembre de 2015.

WAMSLER, Christine. Managing Urban Disaster Risk: Analysis and Adaptation Frameworks for Integrated Settlement Development Programming for the Urban Poor. Tesis doctoral. Lund: Lund University Press, 2007.

World BAnK. World Development Report 2011: Conflict, Security, and Development. Washington D. C.: World Bank, 2011.

WRI. World ResourCe InSTITUTE. Historical Emissions Data, Tools, Reporting, and Analysis for Climate. Washington D. C.: WRI, 2015.

ZALA, Ben. Looking for Leadership: Sustainable Security in Latin America \& the Caribbean. Norwegian Peace Building Centre y Oxford Research Group, 2010, en línea: http://www. resdal.org/experiencias/looking-for-leadership-ene-2010.pdf. Fecha de consulta: 15 de octubre de 2011.

Zambrano, Pablo. Conflicto por el Silala, una oportunidad para la cooperación. Academia Nacional de Estudios Políticos y Estratégicos, 2013, en línea: http://www.anepe.cl/2013/04/ conflicto-por-el-silala-una-oportunidad-para-la-cooperacion/. 
TIPO DE CONFLICTOS CLIMÁTICOS EN ALC

\begin{tabular}{|c|c|c|}
\hline $\begin{array}{c}\text { EVENTO } \\
\text { CLIMÁTICO, } \\
\text { IMPACTO } \\
\text { ESPERADO Y TIPO } \\
\text { DE CONFLICTO } \\
\end{array}$ & $\begin{array}{l}\text { PAÍSES, SUBREGIONES Y } \\
\text { POBLACIONES AFECTADAS }\end{array}$ & $\begin{array}{l}\text { CONSECUENCIAS Y } \\
\text { PERSPECTIVA FUTURA }\end{array}$ \\
\hline $\begin{array}{l}\text { Sequías y escasez } \\
\text { alimentaria: } \\
\text { demandas } \\
\text { al sector de } \\
\text { salud pública y } \\
\text { migraciones }\end{array}$ & $\begin{array}{l}\text { Guatemala. Corredor } \\
\text { Seco: Departamentos de } \\
\text { Jutiapa, Santa Rosa, Zacapa, } \\
\text { Chiquimula, Jalapa, El } \\
\text { Progreso, Baja Verapaz, } \\
\text { Quiché Chimaltenango, } \\
\text { y Huehuetenango. } \\
\text { Asentamientos informales } \\
\text { urbanos y áreas rurales. }\end{array}$ & $\begin{array}{l}\text { En } 2014 \text { la sequía se prolongó y } 236.000 \\
\text { familias perdieron su cosecha de maíz y } \\
\text { frijol, dejándolas sin reservas de alimentos. } \\
\text { Se requirieron Q500 millones en ayuda } \\
\text { humanitaria. Unas } 763.000 \text { personas } \\
\text { podrían afrontar falta de alimentos, } \\
\text { lo cual provocaría alta prevalencia de } \\
\text { desnutrición en niños menores de } 5 \text { años e } \\
\text { incrementaría la morbilidad y mortalidad } \\
\text { infantil (UNETE 2014). }\end{array}$ \\
\hline $\begin{array}{l}\text { Sequías y } \\
\text { demanda hídrica: } \\
\text { tensión social por } \\
\text { acceso al agua } \\
\text { y migraciones } \\
\text { campo-cuidad }\end{array}$ & $\begin{array}{l}\text { Bolivia. Cochabamba y La } \\
\text { Paz, El Alto (una de las } \\
\text { ciudades con crecimiento } \\
\text { más rápido en ALC. Cientos } \\
\text { de miles de personas han } \\
\text { emigrado en busca de } \\
\text { trabajo y oportunidades. } \\
\text { La causa de esta migración } \\
\text { son las frecuentes sequías, } \\
\text { las lluvias erráticas y las olas } \\
\text { de calor que han generado } \\
\text { condiciones difíciles para } \\
\text { el cultivo en áreas rurales) } \\
\text { (Hoffman y Grigera 2013). }\end{array}$ & $\begin{array}{l}\text { La escasez y acceso al agua contribuyeron } \\
\text { a la violencia en el año } 2000 \text { durante } \\
\text { la llamada «Guerra del Agua» en } \\
\text { Cochabamba. Las protestas y el } \\
\text { establecimiento de la ley marcial por el } \\
\text { gobierno causaron la muerte de } 5 \text { personas } \\
\text { muertas y } 40 \text { heridos. La demanda de } \\
\text { agua para irrigación e industria aumentará } \\
\text { en un } 150 \% \text { para } 2020 \text { y en un } 250 \% \\
\text { para } 2050 \text {. Se deberán implementar } \\
\text { estrategias efectivas para la gestión del } \\
\text { agua en condiciones climáticas inciertas } \\
\text { y una respuesta sistemática para proteger } \\
\text { y preparar a los más vulnerables. La } \\
\text { creciente demanda de agua y el rápido } \\
\text { aumento de población urbana junto con } \\
\text { la caída de los suministros glaciares de la } \\
\text { cordillera presenta uno de los retos más } \\
\text { importantes de Bolivia en los próximos } \\
\text { años (PNUD 2011). }\end{array}$ \\
\hline $\begin{array}{l}\text { Demanda } \\
\text { hídrica: conflicto } \\
\text { geopolítico }\end{array}$ & $\begin{array}{l}\text { Chile y Bolivia: cuenca } \\
\text { hidrográfica transfronteriza } \\
\text { del Silala ubicada en el } \\
\text { desierto de Atacama }\end{array}$ & $\begin{array}{l}\text { En } 2013 \text { el gobernador de Potosí, Bolivia, } \\
\text { anunció el corte «inminente» de las aguas } \\
\text { del río Silala que fluyen hacia Chile. Este } \\
\text { y otros proyectos de infraestructura en } \\
\text { el lado boliviano utilizarán el } 100 \% \text { de } \\
\text { los recursos del río. Las aguas del Silala } \\
\text { representan una nueva polémica entre } \\
\text { Bolivia y Chile, enfrentados en la Corte } \\
\text { Internacional de La Haya por el reclamo }\end{array}$ \\
\hline
\end{tabular}




\begin{tabular}{|c|c|c|}
\hline $\begin{array}{l}\text { EVENTO } \\
\text { CLIMÁTICO, } \\
\text { IMPACTO } \\
\text { ESPERADO Y TIPO } \\
\text { DE CONFLICTO } \\
\end{array}$ & $\begin{array}{l}\text { PAÍSES, SUBREGIONES Y } \\
\text { POBLACIONES AFECTADAS }\end{array}$ & $\begin{array}{l}\text { CONSECUENCIAS Y } \\
\text { PERSPECTIVA FUTURA }\end{array}$ \\
\hline & & $\begin{array}{l}\text { boliviano de restitución de su acceso } \\
\text { soberano al mar. De no llegar a un } \\
\text { acuerdo, Antofagasta, la tercera ciudad } \\
\text { más grande de Chile, puede sufrir severa } \\
\text { escasez de agua (Zambrano 2013). }\end{array}$ \\
\hline & $\begin{array}{l}\text { El Acuífero Guaraní: reserva } \\
\text { transfronteriza que se } \\
\text { extiende en los territorios de } \\
\text { Brasil, Argentina, Paraguay y } \\
\text { Uruguay. Es considerado, a } \\
\text { pesar de que se desconoce su } \\
\text { límite oeste sobre territorio } \\
\text { argentino, la tercera reserva } \\
\text { mundial más grande de agua } \\
\text { dulce. }\end{array}$ & $\begin{array}{l}\text { La documentación sobre uso de aguas } \\
\text { subterráneas suele ser confusa e irregular. } \\
\text { Al ser deficiente la información sobre el } \\
\text { uso del agua en general y de la subterránea } \\
\text { en particular, no se ha avanzado en } \\
\text { reglamentaciones que regulen su uso } \\
\text { compartido. Cada Estado deberá tomar } \\
\text { medidas preventivas y ejecutar políticas } \\
\text { a mediano y largo plazo, que permitan } \\
\text { que este recurso se mantenga para bien } \\
\text { no solo de los territorios que lo poseen, } \\
\text { sino también para el resto de la población } \\
\text { mundial (Cosso 2011). }\end{array}$ \\
\hline Olas de calor & $\begin{array}{l}\text { México, D. F., ciudadanos de } \\
\text { la tercera edad y residentes } \\
\text { en asentamientos precarios }\end{array}$ & $\begin{array}{l}\text { El aumento de temperatura en México } \\
\text { D. F. ha alcanzado entre } 33-35^{\circ} \mathrm{C} \\
\text { (Martínez et al. 2010). La población } \\
\text { de la tercera edad se ha incrementado } \\
\text { del 5,1\% en } 1995 \text { al } 6,8 \% \text { en } 2006 \text {. } \\
\text { Se espera que este grupo de edad siga } \\
\text { creciendo. Por ello, una mayor proporción } \\
\text { de la población estará expuesta y será } \\
\text { especialmente sensible a olas de calor. } \\
\text { El aumento de la temperatura afectará } \\
\text { al resto de la población en Ciudad de } \\
\text { México porque los edificios no están } \\
\text { diseñados para enfrentar temperaturas } \\
\text { extremas. Podrán surgir problemas de } \\
\text { salud pues alimentos perecederos se } \\
\text { vencen fácilmente debido a las extremas } \\
\text { temperaturas generando más estrés en el } \\
\text { sistema de salud pública (Ibarran 2011). }\end{array}$ \\
\hline $\begin{array}{l}\text { Generación } \\
\text { energía eólica } \\
\text { afecta morfología } \\
\text { del ambiente } \\
\text { natural: conflictos } \\
\text { sociales y } \\
\text { culturales }\end{array}$ & $\begin{array}{l}\text { Brasil. En 2002, el Gobierno } \\
\text { Federal de Brasil creó el } \\
\text { programa de incentivos } \\
\text { de fuentes alternativas de } \\
\text { energía eléctrica. Desde } \\
\text { entonces, el Estado de Ceará } \\
\text { ha fomentado el desarrollo }\end{array}$ & $\begin{array}{l}110 \text { comunidades asentadas a lo largo } \\
\text { de } 573 \mathrm{~km} \text { de costa donde se ubica el } \\
\text { complejo eólico que dependen de la pesca } \\
\text { artesanal y la agricultura familiar se verán } \\
\text { afectadas por la construcción de molinos } \\
\text { de viento. Las turbinas son desplegadas en } \\
\text { áreas de usufructo de comunidades }\end{array}$ \\
\hline
\end{tabular}



EN AMÉRICA LATINA Y EL CARIBE

\begin{tabular}{|c|c|c|}
\hline $\begin{array}{c}\text { EVENTO } \\
\text { CLIMÁTICO, } \\
\text { IMPACTO } \\
\text { ESPERADO Y TIPO } \\
\text { DE CONFLICTO }\end{array}$ & $\begin{array}{l}\text { PAÍ́SES, SUBREGIONES Y } \\
\text { POBLACIONES AFECTADAS }\end{array}$ & $\begin{array}{l}\text { CONSECUENCIAS Y } \\
\text { PERSPECTIVA FUTURA }\end{array}$ \\
\hline & $\begin{array}{l}\text { de fuentes alternativas } \\
\text { de energía, en particular, } \\
\text { energía eólica. En } 2010, \\
\text { Ceará era el estado con } \\
\text { mayor número de parques } \\
\text { eólicos (17 proyectos con } \\
\text { capacidad instalada de } \\
500 \mathrm{MW} \text { ). El Complejo } \\
\text { Baleia comprende seis } \\
\text { parques eólicos en la zona } \\
\text { costera de playas Baleia y } \\
\text { Maceió, que implica una } \\
\text { interrupción morfológica } \\
\text { porque las dunas están } \\
\text { perdiendo su formación } \\
\text { natural, su movilidad y, en } \\
\text { consecuencia, su función } \\
\text { para evitar la erosión. }\end{array}$ & $\begin{array}{l}\text { tradicionales y dentro de manglares. De } \\
\text { acuerdo a estudios de la Universidad } \\
\text { Federal de Ceará, la producción de } \\
\text { energía eólica causa impactos negativos } \\
\text { sobre el ambiente. En la instalación de } \\
\text { turbinas eólicas vías de acceso fueron } \\
\text { construidas sobre dunas móviles, lo que } \\
\text { afecta a sistemas lacustres y perturban } \\
\text { la dinámica ambiental. El estudio señala } \\
\text { otros impactos: contaminación del aire, } \\
\text { falta de empleo y acoso sexual a mujeres } \\
\text { por trabajadores que instalaron los } \\
\text { molinos de viento (Enviornmental Justice } \\
\text { Atlas 2016). }\end{array}$ \\
\hline & $\begin{array}{l}\text { Brasil. La Reserva de } \\
\text { Desarrollo Sostenible de } \\
\text { Ponta do Tubarao (SDR-PT) } \\
\text { fue creada en } 2003 \text { después } \\
\text { de una década de luchas } \\
\text { de comunidades locales } \\
\text { y activistas en contra de } \\
\text { diversos proyectos en el } \\
\text { área (incluyendo un centro } \\
\text { turístico y criaderos de } \\
\text { camarones a lo largo de } \\
\text { los manglares). En la SDR- } \\
\text { PT habitan poblaciones } \\
\text { tradicionales fuertemente } \\
\text { unidas al territorio. Las } \\
\text { comunidades aseguran su } \\
\text { subsistencia por medio de } \\
\text { pesca artesanal y mariscos, } \\
\text { turismo comunitario, así } \\
\text { como pequeña agricultura y } \\
\text { cría de animales. }\end{array}$ & $\begin{array}{l}\text { Desde } 2010 \text { dos proyectos de energía } \\
\text { eólica comenzaron a operar dentro de } \\
\text { la SDR-PT: Miassaba Alegria I y II. El } \\
\text { gobierno del estado apoya la instalación } \\
\text { de estas empresas. Las vías de acceso están } \\
\text { construidas sobre las dunas móviles, lo } \\
\text { que afecta la pesca, actividad cotidiana de } \\
\text { sus habitantes. Los lugareños afirman que } \\
\text { la construcción de carreteras ha creado } \\
\text { escasez de agua y los estanques están } \\
\text { secos. La construcción de un muro y la } \\
\text { línea de torres interrumpen la conexión } \\
\text { hidrológica entre ríos y el mar. Esto afecta } \\
\text { el acceso de pescadores y la alteración de } \\
\text { las arenas de agua afecta las actividades } \\
\text { pesqueras. Las carreteras construidas y } \\
\text { la eliminación de dunas impiden el libre } \\
\text { tránsito de peces y canoas. La producción } \\
\text { de energía eólica está causando impactos } \\
\text { negativos sobre el medio ambiente } \\
\text { (Environmental Justice Atlas 2016). }\end{array}$ \\
\hline
\end{tabular}

Fuente: Elaboración propia. 